\title{
BASIC RADIO PROPAGATION PREDICTIONS FOR APRIL 1946
}

\section{THREE MONTHS IN ADVANCE}

ISSUED

JANUARY 1946

PREPARED BY INTERSERVICE RADIO PROPAGATION LABORATORY National Bureau of Standards Washington 25 , D. C. 


\section{BASIC RADIO PROPAGATION PREDICTIONS FOR APRIL 1946 THREE MONTHS IN ADVANCE}

The monthly reports of the IRPI - $D$ series are distributed to the Army as the TE $11-496$ series, by the Adjutant Gereral; to the Navy as the DNC-13-1 series, by the Registered I'ublications Section, Division of Naval Communications: and to other's hy the IRPL.

This IRPL-D series is a monthly supplement to the IRPL Radio Propagation Handbook. Part 1, issued by the Army as TM 11-499 and by the Navy as DNC-13-1, and is required in order to make practical application of the basic Handbook.

Comments are invited from users of this report as to the accuracy of predictions when applied to the solution af specific radio propagation problems. Such comments or queries concerning radio propagation should be aldiessed as follows:
For the Armm:

Hearlquarters, Army Service Forres.

oflice of the chief Signal officer.

Waslington 25, D. C.

Attention: SPsol.

F'or the Nory:

chiel of Naval Operations,

Navy Tenartment,

Washington 25, D. C.

( I N $(-20-\mathrm{F})$.

Fin others:

Intriservice Radio Propagation Lahoratory,

National Bureau of Stamlards.

Washington 25, 5. O.

\section{CONTENTS}

I. Terminologr-ar. Page 2

World mal showing zones covered by prediction charts, and auroral zones_-_ Fig. 1

Fo-zero-muf, in IIc, If zone, preslicted for April 1946_ Fig. 5

F2-4000-muf, in Mc, W zone, predicted for April 1946

Fo-zero-muf, in Me, I zone, predicted for

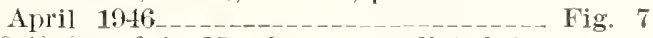

$F^{2}$-fouo-muf, in IIc, I zone, predicted for April 1946_____._. Fig. \&

Fa-zero muf, in Mc, $E$ zome, predicted for April 1946______ Fig. 9

$F$ - 4000 -muf, in MC, $E$ zone, predicted for

April 1946 Fig. 10

E-layer 2ono-mut, in He, predicted fol April 1946 Fig. 11

Median fEs Me, predicted for April 1946_ Fig. 12

Percentage of time occurrence for $E s$ in

excess of $15 \mathrm{Mc}$, predicted for April 1946_ Fig. 15

III. Determination of great-circle distances, bear-

ings, location of transmission control

points______. Page 2

Great-circle chart, centersd on equator-- Fig. 2

Diagram of transmission path auxiliary to explanation of use of distance-hearing nomogram, figure 4 Fig. 3
III. Determination, etc-Continued.

Nomogram for obtaining great-circle distances, hearings, latitude and longitude of transmission control points. Conversion scale for various distance units____

IV. Galculation of maximum usable frequencies, optimum working frequencies._. l'aget

Nomograms for transforming Fo-zero muf and $F 2-4000$-muf to equivalent maximum usable frequencies at intermediate transmission distances: conversion soale for ohtaining optimum working frequencies_-

Nomogram for transforming $E$-layer $2000-$ muf to equivalent maximum usable frequencies and optimum working frequencies dur to combinesl effect of $E$ layer and $F 1$ hayer at other transmission distances-

$V$. Absorption, distance range, and lowest useful

high frequeney _ Page 6

Vl. Sample muf and owf calenations________ T'age 6

For short paths (under $4000 \mathrm{~km}$ ) page 6 , table 1 , and figure 16 .

For long paths (over $4000 \mathrm{~km}$ ) page 7 , table 2, and figure 17. 


\section{TERMINOLOGY}

The following symbols are used, as recommended by the International Radio Propagation Conference held in Washington, D. C., 17 Aproil to 5 May 1944.

$$
\begin{aligned}
& f \circ F=\text { ordinary - wave critical fre- } \\
& \text { quency for the } F 2 \text { layer. 'The } \\
& \text { term night } F \text { layer will no } \\
& \text { longer be used. The term } F 2 \\
& \text { layer is now used for the } \\
& \text { night } F \text { as well as the day- } \\
& \text { time } F 2 \text { layer. } \\
& f^{\circ} F 2=\text { extraordinary-wave critical fre- } \\
& \text { quency for the } F 2 \text { layer. }
\end{aligned}
$$

$E s=$ sporadic, or abnormal $E$.

$f E s=$ highest frequency of $E s$ reflections.

muf or $\mathrm{MUF}=$ maximum usable frequency.

owf or OWF= optimum working frequency .

4000-muf chart $=$ contour chart of muf for 4000 kilometer paths.

2000-muf chart $=$ contour chart of muf for 2000 kilometer paths.

Zero-muf chart= contour chart of rertical-incidence critical frequency, extraordinary wave.

Note. - The designation $F F_{2}$ has been replaced by $F_{2}$.

\section{WORLD-WIDE PREDICTION CHARTS AND THEIR USES}

The charts, figures 5 to 11 , present world-wide predictions of monthly average maximum usable frequencies for April 1946. Conditions may be markedly different on disturbed days, especially in or near the anroral zones, shown on the map of figure 1. The method of prediction is discussed in the IRPL Radio Propagation Handbook. Part 1. War Dept. TM 11-499. Navy Dept. DNC-13-1. p. 52,53 .

Although ionosphere characteristics are roughly similar for locations of equal latitude, there is also a considerable rariation with longitude, especially in the case of the Fo layer. "This "Iongiturle effect" seems to be related to geomanetic latitude. Attention was first called to this effert in the report "Radio Propagation Conditions" issued 10 Sept. 1943 ; it was brought into general operational use in the next issue (14 Oct. 1943).

'The longitude effect in the FD layer is taken care of by providing world charts for three zones, in each of which the ionosphere characteristics are comsidered independent of longitude, for practical purposes. These zones are indicated on the worli map, figure 1.
Two Fo charts are provided for each zone. one of which, the "zero-muf chart," shows the rerticalincidence muf, or the critical frequency for the extraordinary wave, and the other, the " 4000 muf chart." shows the muf for a transmission distance of $4000 \mathrm{~km}$. Do not confuse the zero-muf charts with the $f^{\circ} F \cdot 2$ charts appearing in the previous IRPL, reports "Radio Propagation Conditions." (Values of $F$-zero-muf exceed those of $f^{\circ} \mathrm{F}:$ for the same location and local time by an amount approximately equal to half the gyrofrequency for the location. See IRPL Radio Propagation Handbook, Part 1 (War Dept. 'TM 11-199 and Nary Dept. DNC-13-1), p. 18, 19. 28, and fig. 9).

The longitude variation is operationally negliwible in the case of the normal $E$ layer and therefore only one $E$-la yer chart is provided.

The variation of $f E s$ with geomagnetic latitude seens to be well marked and important. Consequently, the fEs charts are constructed on the basis of geomagnetic latitude. Since there are. as yet, insufficient correlated data, the fEs charts are much less precise than the other charts. Instructions for use of these charts appear in section IV. 3.

\section{DETERMINATION OF GREAT-CIRCLE DISTANCES, BEARINGS, AND LOCATION OF TRANSMISSION CONTROL POINTS}

\section{BY USE OF THE WORLD MAP AND GREAT-CIRCLE CHART}

Finule 1 is a map of the wolld. Figure 2 in a chat to the same scale as figure 1 , on which the solicline curves crossing the equator at a single point represent wreat circles. The numbered dotdash lines crossing the great circles indicate distances along them in thonsands of kilometers. In using figures 1 and 2 proceed as follow: a. Place a piece of transparent paper over the map, figme 1, and draw the equatorial line (zero (legrees). Place dots over the locations of the transmitting and receiving stations. Also mark the neridian whose local times are to be used as the times for calculation. Tsually the Greenwich meridian is used. 
b. Place this transparency over the clart, figure 2 , and, keeping the equatorial line of the transparency always on the equatorial line of figure 2 , slide the transparency horizontally until the terminal points marked on it fall either on the same great circle or the same proportional distance between arjacent great-cincle curves. Draw in the path.

c. For paths shorter than $4000 \mathrm{~km}$, locate the midpoint of the path, keeping the transparency in position on figure 2 and using as a distance scale the points at which the numbered lines in figure 2 cross the path as drawn on the transparency.

d. For paths longer than $4000 \mathrm{~km}$, designating the ends as the 1 -ent and $B$-end, respectively, loate on the path and mark with a dot the following "control points," sealing the distances as in $c$ above:

For $F 2$ layer, points $A$ and $B, 2000 \mathrm{~km}$ from each end.

For $E^{\prime}$ layer, points $A^{\prime}$ and $P^{\prime}, 1000 \mathrm{~km}$ from each end.

\title{
2. BY USE OF THE NOMOGRAM OF FIGURE 4
}

\begin{abstract}
Note-Valnes near the ends of the nomogram scales of figure $t$ are suliject to error because the scales are compressod. If exict ralues are ropuired in those regions, they should be calculated by meims of the nsual trigonometrie formulas.
\end{abstract}

In figure $3, Z$ and $S$ are the locations of the transmitting and receiving stations, where $Z$ is the west and $S$ the east end of the path. If a point Ties in the Southern Hemisphere, its angle of Tatitude is always taken as negative. Northern-Hemisphere latitudes are taken as positive.

a. To obtain the great-circle distance ZS (short route) :

(1) Draw a slant line from (lat. Z-lat. $S$ ) measured up from the bottom on the left-hand scale to (lat. $Z$ +lat. S) measured down from the top on the right-hand scale. If (lat. Z-lat. S) or (lat. $Z+$ lat. $S$ ) is negative, regard it as positive.

(2) Determine the separation in longitude of the stations. Regard as positive. If the angle so obtained is greater than $180^{\circ}$, then subtract from $360^{\circ}$. Measure this angle along the botom scale, and erect a vertical line to the slant line obtained in (1).

(3) From the intersection of the lines draw a horizontal line to the left-hand scale. This gives ZSS in degrees.

(4) Convert the distance $Z S$ to kilometers, miles or nautical miles, by using the scale at the bottom of figure 4.

Note.-The long grat-circle route in degrees is simply $360^{\circ}-Z S$. The value will always be greater than $180^{\circ}$. Therefore in order to obtain the distance in miles from the conversion scale, the value for the degrees in excess of $180^{\circ}$ is added to the value for $180^{\circ}$.

\section{To obtrin the bearing angle PZS (short route):}

(1) Subtract the short-route distance $Z S S$ in degrees obtained in a from $90^{\circ}$ to get $h$. The value of $h$ may be negative, but should always be regarder as positive.

(2) Draw a slant line from (lat. $Z-h$ ) measured up from the bottom on the left-hand seale to (lat. $Z+h$ ) measured down from the top on the right-hand scale. If (lat. $Z-h$ ) or (lat. $Z+h)$ is negative, regard it as positive.

(3) From $\left(90^{\circ}\right.$ - lat. S) measured up from the bottom on the left-hand scale, draw a horjzontal line until it intersects the previous slant line.

(4) From the point of intersection draw a vertical line to the bottom scale. This gives the bearing angle $P Z S$. The angle may be either east or' west of north, and nust be determined by inspection of a map.

\section{c. To obtain the bearingangle PSZ:}

(1) Repeat steps (1), (2), (3), and ( 1 ) in $b$, interchanging $Z$ and $S$ in all computat ions. The result obtained is the interior angle PSZ, in degrees.

(2) The bearing angle PSZ is $360^{\circ}$ minus the result obtained in (1) (as bearings are customarily given clockwise from (lue north).

Note.-The long-ronte bearing angle is simply obtained by adding $180^{\circ}$ to the short-route value as determined in $b$ or $c$ above.

\section{d. To obtain the latitude of $Q$ (mid-or other point of path):}

(This calculation is in principle the converse of 6.$)$

(1) Obtain $Z Q$ in degrees. If $Q$ is the midpoint of the path, $Z Q$ will be equal to one-half $Z S$. If $Q$ is one of the $2000-\mathrm{km}$ "control points," ZQ will be approximately $18^{\circ}$, or $Z S^{\prime}-18^{\circ}$.

(2) Subtract $Z Q$ from $90^{\circ}$ to get $h^{\prime}$. If $h^{\prime}$ is negative, regard it as positive.

(3) Draw a slant hine from (lat. $Z-h^{\prime}$ ) measured up from the bottom on the left-hand scale, to (lat. $Z+h^{\prime}$ ) measured down from the top on the right-hand seale. If (lat. $z-h^{\prime}$ ) or (lat. $\left.Z+h^{\prime}\right)$ is negative. regard it as positive.

(4) From the bearing angle P'ZS (taken always as less than $180^{\circ}$ ) measured to the right on the botton scale, draw a vertical line to meet the above slant line.

(5) Fron this intersection draw a horizontal line to the left-hand scale.

(6) Subtract the realing given from $90^{\circ}$ to give the latitude of ?. (If the answer is negative then $Q$ is in the southern Hemisphere.) 
e. To obtain the Tongitude difference t' between $Z$ and $Q$ :

(This calculation is in principle the converse of $a$.)

(1) Draw a straight line from (lat. Z- lat. Q) measmexl up from the bottom on the left-hand scale to (lat. $Z$ +lat. $Q$ ) measured down from the top on the right-hand seale. If (lat. $Z$-lat. $Q$ ) or (lat. $Z+$ lat. $Q)$ is negative. peard it as positive.

(2) From the left-hand side, at $Z Q$, in degrees, draw a horizontal line to the above slant line.

(3) At the intersection drop a vertical line to the bottom scale, which gives $t^{\prime}$ in degrees.

\section{CALCULATION OF MAXIMUM USABLE FREQUENCIES, OPTIMUM WORKING FREQUENCIES}

\section{PROCEDURE FOR DETERMINATION OF MUF AND OWF FOR TRANSMISSION DISTANCES UNDER 4000 KM (PROPAGATION BY THE REGULAR LAYERS)}

a. Prepare or secure work forms similar to IRPL form $\triangle F$ (see table 1 ). Note that form $\Lambda F$ provides for the inclusion of sporadic $E(E s)$, which will be discussed under (3) below.

b. Locate the midpoint of the transmission path, using the methods of section III above and by laying the great-circle path transparency back on the world map of figure 1, with the ends of the path in their proper location, determine in which geographical zone, $E, I$, or $W$, the midpoint falls.

c. To deternine the maximm usable frequency (muf) :

(1) Place the great-cirele transparency over the F2-zero-muf chart for the proper zone of the midpoint of the path. and, keeping the equatorial line of the transparency over the equatorial line of the chart, slicle the transparency lorizontally until the Greenwich meridian coincides with $00^{\circ}$ on the time scale. Note that all points on the great-circle path are in their proper local time relationship to Greenwich hecanse 24 homls on the time seale of a muf ehart is drawn to the same scale as $360^{\circ}$ of longiturle on the world map.

(2) Read the value of $7^{*}$-zero-muf for the midpoint of the path and enter in column $d$ of form LF.

(3) Repeat for 02,04, etc. on the time scale.

(4) Riepeat steps (1), (2), and (3) for the F2-4000-muf chart for the proper zone and again for the $E$-layer 2000 -muf chart, figure 11, entering values in collummse and $e$, respectively.

(5) For each hom place a straightedge between the values of Fo-zoro-muf and Fo-toog-muf at the left-and right-hand sides. respectively, of the grid nomogran, fignre 1:3, and rearl the value of the muf for the actual path length at the intersection point of the straightedge with the appropriate rertical distance line. Enter in column $h$. Example:

F⿻-zero-muf $=6.8 \mathrm{Mc} . \quad F \circlearrowright-4000$ - $\mathrm{muf}=23.0 \mathrm{Mc}$.

For a distance of $2600-\mathrm{km}$ the $F 2$ muf is 19.1 Mc.

(6) For each hom place a straightedge between the value of the E-layer 2000 -muf on the left-hand scale of the nomogram. figme 14 . and the value of the path length on the right-hand scale. and read the $E-F 1$-nut for that path length, off the central sale. (Example on nomogram.) Enter in column $g$.

(7) Compare the values of muf obtained by operations (1) to (6). The higher of the two values (columns $g$ and $h$ of form $A F$ ) thus determined is the muf for the path. Enter in column m.

\section{d. To determine the optimm working frequency} (owf):

(1) Calculate the $F \cdot$-owf from the $F 2$-muf determined under $c$ above by multiplying by $0.85 \mathrm{or}^{\circ}$ nsing the conversion seale in figure 13. Enter in columint 7 .

(2) Use for the E-F1-owf the value of $E-F 1$ muf determined under $c,(6)$ above. This represents a change from the previous practice of taking 97 percent of the E-F 1-muf on the nomogram of figure 1t. Enter in column $k$.

(3) Compare the F2-owf and E-F1-owf. The higher of the two values (columns $k$ and $l$ of form $\Delta \mathrm{F}$ ) is that of the path owf. Enter in cohmn $n$.

\section{PROCEDURE FOR DETERMINATION OF MUF AND OWF FOR TRANSMISSION DISTANCES GREATER THAN $4000 \mathrm{KM}$ (PROPAGATION BY THE REGULAR LAYERS)}

a. General considerations:

The procedure ontlined below is based on the following assumptions:

(1) 'That there atre Fy-layer control points a and $I^{\prime}$ and $E^{\prime}$ - a yer contol points $l^{\prime}$ and ${ }^{\prime}{ }^{\prime}$. (Seesection III, 1 d above.)

(2) 'That the highest frequency that will "take ofl" along the path at the 1 -end is the highest frequency that can be propagated at 1 and $A^{\prime}$ comsidered together.

(3) That the highest frequency that will come in along the path at the $B$-end is the highest freenency that can be mopagated at $B$ and $B^{\prime}$ considered together.

(4) That the highest frequency that can be propagated from the $A$-end to the $B$-end is the tocer of the 1 wo frequencies of (2) and (3) above. 
(5) That the frequency obtained in ( 4$)$ is the same for propagation from the $B$-end to the A-end.

b. Prepare or secure work forms similar to IRPL form $\mathrm{AH}$ (see table 2). Note that form AH provides for the inclusion of the effects of sporadic $E(E s)$, which will be discussed under 3 below.

c. Locate the control points a and at' at one end of the patli and $P$ and $Z^{\prime}$ at the other end of the path as explained under section III, $1, d$ above. For very long paths the "short route" (minor are of the great-circle path) and the "long route" (major arc) need be considered. Placing the transparency back on the world map, determine as in section IV, $1, b$ above in which geographical zone, $E . I$ or $W$. each of the control points 1 and $B$ falls.

\section{d. To determine the mut:}

(1) Place the great-circle transparency over the F2-4000-muf chart for the proper zone of the midpoint of the path for control point at and, keeping the equatorial line of the transparency over the equatorial line of the chart, slide the transparency horizontally until the Greenwich meridian coincides with 00 on the time scale.

(2) Read the value of $F D$ - fom-muf for control point A. Enter in column $c$ of form XII.

(3) Repeat for 02, 04 etc. on the time scale.

(4) Repeat steps (1), (2), and (3) on the $E$ layer 2000-muf chart, figure 11, using control point $A^{\prime \prime}$. Enter values in columin $d$.

(5) Determine the muf for the t-end as the higher of the $F 2-4000-m u f$, column $r$, and the $E$ layer 2000-muf, column $d$. Enter in column $m$.

(6) Read the value of Fo-4000-muf for cont $\mathrm{mol}$ point $B$, using the $F 2-4000$-muf chart for the proper zone. Enter values in column $i$.

(7) Repeat for 02, 04, otc. on the tine scale.

(8) Read the values of $E$-layer 2000-nuf on the E-layer 2000-muf chart, figure 11, using control point $B^{\prime}$. Enter values in column $j$.

(9) Determine the muf for the $B$-end as the higher of the $F 2-4000-m u f$ columm $i$, and the $E$ layer 2000-muf, column ;. Enter in column $n$.

(10) Compare the two muf values of columns $m$ and $n$. The lower of the two is the muf for the transmission path unter consideration. Enter in column $q$.

e. To retermine the owf:

(1) Use the scaled data of the previous procedure.

(2) Multiply the $F 2-4000$-muf for the L-end. column $c$, by 0.85 , or use the conversion seale in figure 13, to obtain the $F \cdot 1000$-ow for the 1 -end, column $f$.

(3) Multiply the F2-4000-muf for the $B$-end, column $i$, by 0.85 or use the conversion scale in figure 13, to obtain the $F-4000$-ow f for the $B$-end, column $?$.

(4) Compare the FQ-4000-ow f for the I-end, column $f$, with the $E$-layer 2000 -muf for the d-end, column 7 . The higher of the two is the owf for the 1-end. Enter in columm o.

(5) Compare the F2-4000-owf for the $B$-end, column 7, with the $E$-laver 2000 -muf for the $B$-end, column ;. The higher of the two is the owf for the B-end. Enter in columm $p$.

(6) Compare the two owf values of columns o and $\%$. The lower of the two is the owf for the transmission path under consideration. Enter in columin $r$.

\section{PROCEDURES FOR INCLUSION OF THE EFFECTS OF ES}

Sporadic-E (Es) propagation may often allow regular transmission when regular $E^{\prime}$ - or Fo-layer propagation would not. Es data are not yet sufficient to permit accurate calculations of such propagation, but the $f E s$ charts of figures 12 and 15 are given as a guide to $E$ s occurrence.

Is the fE's charts are constructed from considerations of geomanetic latitude, three latitude scales are provided at the right of the charts of figures 12 and 15 , one for each of the three zones of figuce $1(\mathrm{E}, I$, and $W)$.

Until further improvements are made, the following procedures should be used to include the effects of $E$.s in the calculations of muf and owf.

a. For paths over $4000 \mathrm{~km}$ long:

(1) Place the ereat-circle path transparency prepated in section III, 1 . over the median $f^{2}$ s chart, figure 12. using the latiturle scale for the zone containing the control point.

(2) Scale $E^{2}$ s at control point $1^{\prime}$ and $B^{\prime}$. Enter in columns $a$ and $\%$ respectively. on form $\mathrm{A} \mathrm{I}$.

(3) Multiply fEs by , in each case, obtaining the Ex-2000-mulf. Enter in columns b and h. respectively.

(4) In the determination of nuf modify the procedure (steps (5) and (9)) of section IV, $2, d$ above to obtain the muf for the 1 - and $B$-ends. respectively, as the highest of the three items, the Fo-4000-mint, the E-layer 2000-muf, and the Es2000-muf. No othei change is neersary.

(5) In the determination of owf subtract $4 \mathrm{Mc}$ from the Es-2000-muf to obtain the Es-2000-owf for the t-end and $B$-end, respectively, entering the results in columnse and h. Then modify the procedure (steps (4) and (5)) of section IV, 2.e to obtain the owf for the t-and li-ends, respectively, as the highest of the three items, the Fo$400-1$, we the E-Tayer 2000 -muf, and the ES-2000owf. No other changen are necessary.

b. For paths under $4000 \mathrm{~km}$ long:

(1) Repeat step (1) of a above.

(2) Soale fEs at the mirlpoint of the path. Enter in column a of form $\Lambda \mathrm{F}$. 
(3) Multiply fEs by 5. obtaining the Es-2000muf. Enter in column $b$.

( 4 ) In the determination of muf under IV, $1, c$, find the $E \&$-muf for the path by use of the same nomogram, figure 14 , as was used for the $E-F 1$ muf, applying the Es-2000-nuf on the left-hand scale and reading the answer on the middle scale. Enter in column $f$. Then modify the procedure in IV. 1, c. (T) so that the highest of the three vilues, the Fo-muft, the E-F1-muf, and the Es-muf, colunns $h, g, f$, is the muf for the path.

(5) In the determination of owf under IV $1, d$, subtract 4 Me from the Es-2000-muf found under (3) above to obtain the Es-2000-owf, entering in column i. Now find the Es-owf for the path, using the same nomogram. figure 14 , as for the $E-F 1$ owf, applying the Es-2000-owf to the left-hand scale and reading the answer on the middle scale Enter in column $;$. Then modify the procedure in section $\mathrm{IV}, 1 . d(3)$ so that the highest of the three values, the $F 2$-owf, the $E-F 1$-owf, and the Es-owf, columns $7, k, j$, is the owf for the path.

Because of the variable nature of $E s$. and the relative uncertainty with which $E s$ is known, caution should be used in the application of Es-owf, particularly for short paths. While transmission should take place most of the time on Es-owf, fluctuations in Es may at times interlupt service. It is thus often desirable to operate near the owf for the regular layers $(E, F 1, F 2)$ only, without the inclusion of E's, although transmission may take place more than 80 percent of the time near the Es-owf.

\section{ABSORPTION, DISTANCE RANGE, AND LOWEST USEFUL HIGH FREQUENCY}

The procedures outlined in the text of this report will give an adequate solution to most of the high-frequency propagation problems that will normally be encountered in the field. If operating frequencies are chosen near the calculated owf prediction in any given case, best possible results should be had. at least in communications work.

The use of frequencies too far below the owf will result in weak reception because of increasing ionospheric absorption as the frequency decreases. 'The faetor that limits the usefulness of low field intensities is usually atmospheric noise at the receiving location.
The determination of lowest useful high frequencies is more difficult than the determination of muf and the techniques for their prediction are less far advanced.

The subject of absorption, distance range, and lowest useful high frequency is discussed at length in IRPL Radio Propagation Handbook. Part 1, p. 69-97 (War Dept. TM 11-499, Navy Dept. DNC-13-1), and formulas, graphs, and nomograms for calculation are given there.

Simpler and more accurate techniques are being leveloped and will be released as soon as the work is completed.

\section{SAMPLE MUF AND OWF CALCULATIONS}

\section{FOR SHORT PATHS}

Required: 'The muf and owf for transmission between Washington, D. C. $\left(39.0^{\circ} \mathrm{N}, 77.5^{\circ} \mathrm{W}\right)$ and Miami, Fla. $\left(25.7^{\circ}\right.$ N. $\left.80.5^{\circ} \mathrm{WV}\right)$ for average conditions during the month of $\triangle$ pril 1946.

\section{Solution:}

Let the local time used for this problem be GCT ( $\%$ time or that of $0^{\circ}$ longitude).

The midpoint of the path is at approximately $32.5^{\circ} \mathrm{N}, 79.0^{\circ} \mathrm{W}$, and the transmission path length is approximately $1500 \mathrm{~km}$, all in $W$ zone.

Ther values of $E$ - and $F 2$-laver muf and ow $f^{2}$ and also $E$ s-owf for even hours, GCT, as determined by using the procedure given in section IV. are given in table 1 . The final values are presented Earphically in figure 16.

Values of owf obtained by the procedure of section IV. 1, c for the regnilar layers only are undersoned in columms $k$ and 7 of table 1 . and are plotted in figure 16. Values of Ex-owf in columm $;$ did not govern at any hour. Consequently, the solid line curve of owf is for the regular layers only.

Figure 16 shows that skip will occur, on the a verage, during the night hours, if a frequency as high as $9.5 \mathrm{Mc}$ is used. A frequency as high as 8.0 Me will not skip, on the average. at any time of day, but its use is not advisable because of (a) the day-to-day variability, causing some probability of skip during the night hours, and (b) ionospherie absorption during the daytime, which is more pronounced at low frequencies.

A satisfactory plan to insure continuous transmission at all times, over a path like this, involves the use of two frequencies, one for night and one for day. Figure 16 shows that a night frequency of $7.0 \mathrm{Mc}$, to be used fiom 0110 to $1245 \mathrm{GCT}$. and a day frequency of $12.5 \mathrm{Mc}$, to be used from 1245 to 0110 GCT, would he satisfactory. The periods of unefulness of these frequencies are shown by the heary dashed line on figure 16. 


\section{FOR LONG PATHS}

Required: The muf and owf for transmission between Washington, D. C. $\left(39.0^{\circ} \mathrm{N}, 77.5^{\circ} \mathrm{W}\right)$ and Tehran, Iran $\left(35.6^{\circ} \mathrm{N}, 51.5^{\circ} \mathrm{E}\right)$ for average conditions during the month of April 1946.

Solution:

Let the local time for this problem be GC'T ( $Z$ ) time or that of $0^{\circ}$ longitude).

The path length is approximately $10,250 \mathrm{~km}$, and the two F2-layer control points, $A$ and $B$, respectively, are at approximately $51.5^{\circ} \mathrm{N}, 59^{\circ} \mathrm{W}$, and $48.5^{\circ} \mathrm{N}, 34.5^{\circ} \mathrm{E}$. These are, respectively, in the $W$ zone and the $I$ zone, as shown on the map, figure 1. The two $E$-layer and $E s$ control points, $A^{\prime}$ and $B^{\prime}$, respectively, are located at approximately $45^{\circ} \mathrm{N}$, $71.5^{\circ} \mathrm{W}$, and $42.5^{\circ} \mathrm{N}, 44^{\circ} \mathrm{E}$. These are in the $W$ and $E$ zones, respectively.

The values of muf and owf over this transmission path, as determined by the procedure in section IV, are given in table 2 for even hours, GCT. The final values are shown graphically in figure 17.

Figure 17 shows that skip will occur, on the a verage, during the night hours if a frequency as high as 12.0 Mc is used, although higher frequencies may be be used during a limited portion of the day.
A good, practical arrangement to insure continuous transmission at all times is to select three frequencies, in a manner similar to that suggested in the preceding problem. A frequency of $9.7 \mathrm{Mc}$ may be used from 2145 to 0920 GCT, a frequency of 15.0 Me may be used from 1100 to 1915 GC'T and a transition frequency of $11.2 \mathrm{Mc}$ may be used from 0920 to 1100 , and from 1915 to $2145^{\circ} \mathrm{GCT}$.

By inspection of the absorption chart and the noise map (figs. 83 and 119 of the IRPL Radio Propagation Handbook, Part 1, War Dept. 'TM 11-499, Navy Dept. DNC-13-1), it may be seen that considerations of the lowest useful high frequency over this path may be of considerable importance in selecting frequencies for use. Consequently, in cases of transmission failure on the frequencies here recommended, particularty in the case of the transition frequency, changing the frequency to a value slightly under the muf for the path may be advisable.

The bearing of Tehran from Washington is approximately $43.5^{\circ}$, and that of Washington from Tehran is approximately $319^{\circ}$, both determined by means of the nomogram of figure 4. 


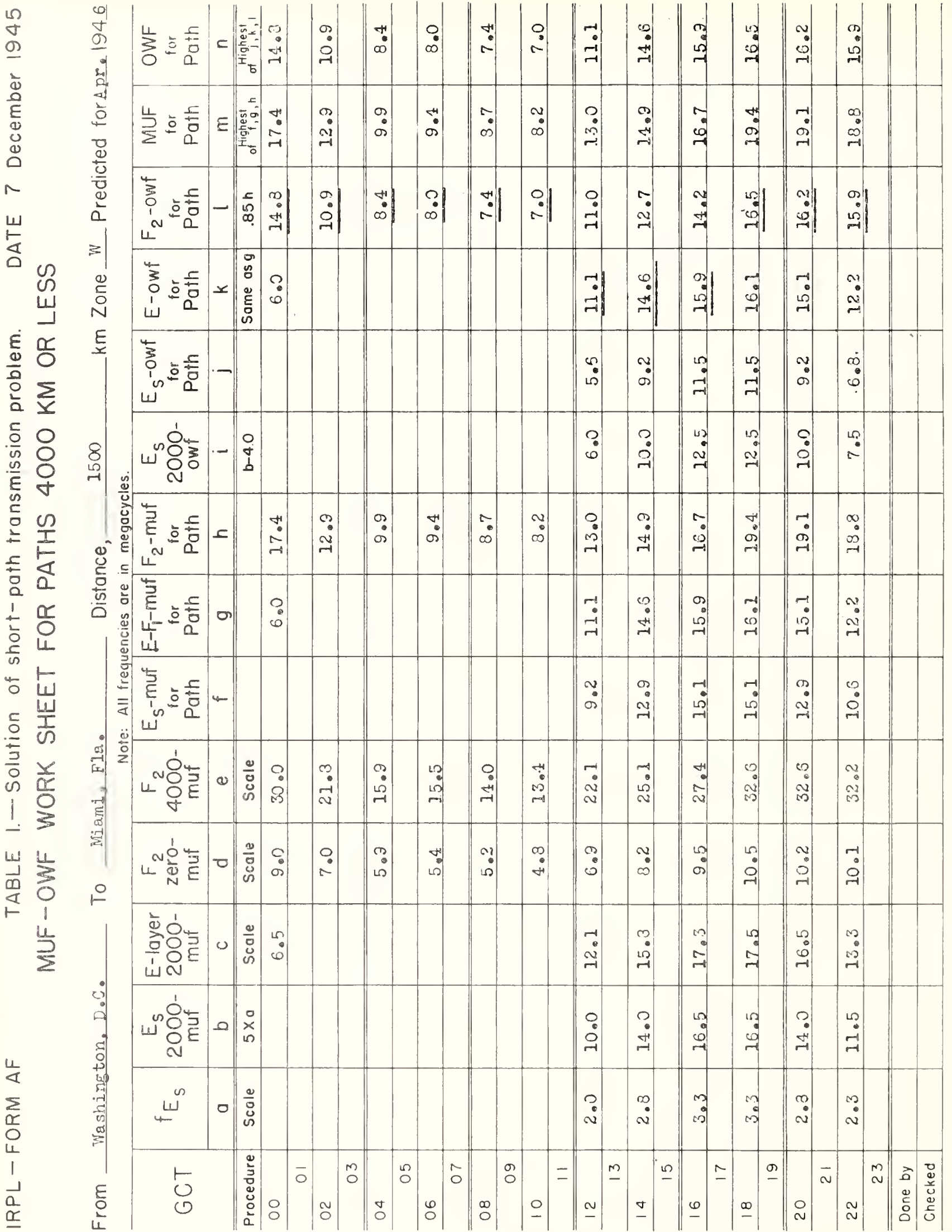




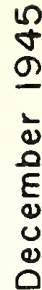

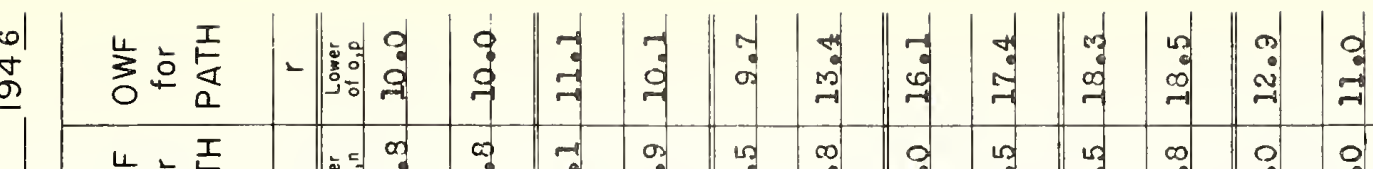
岂点运

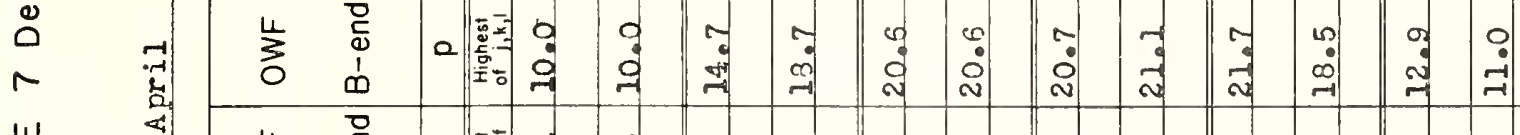

崖

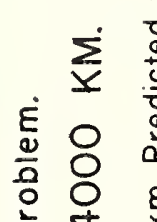
후

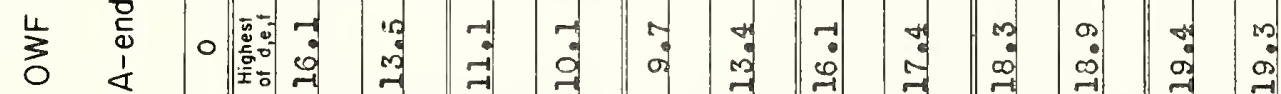
岂

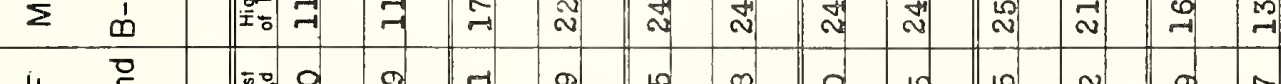

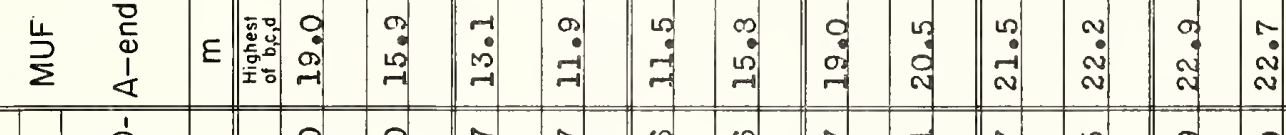

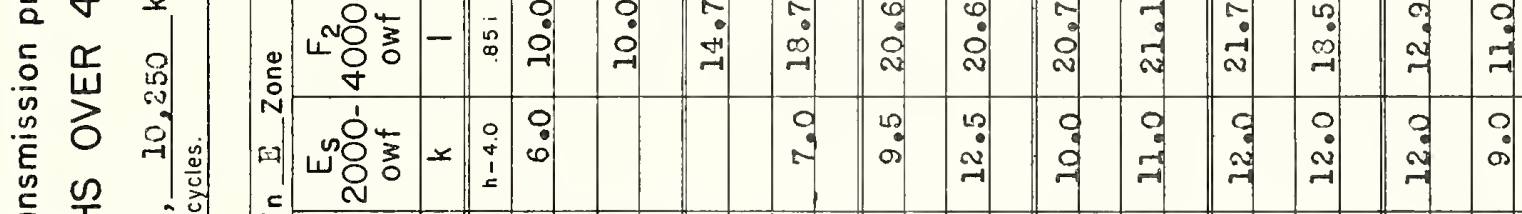

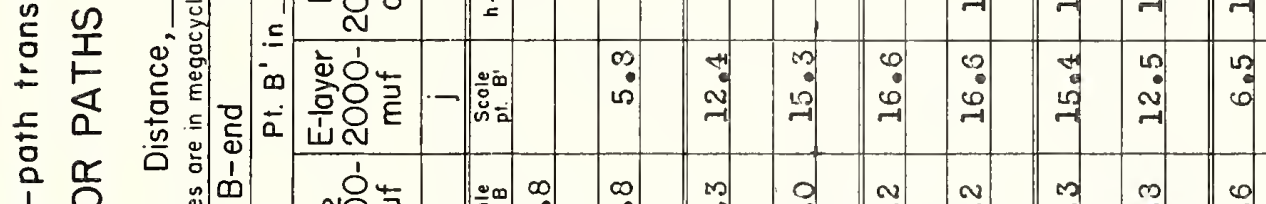

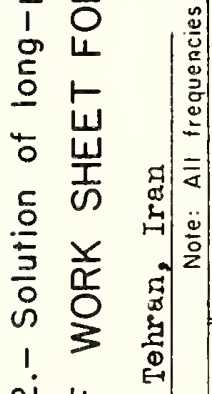

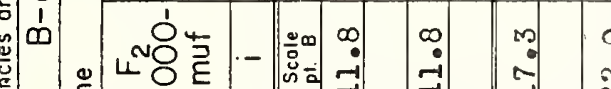

ถับ

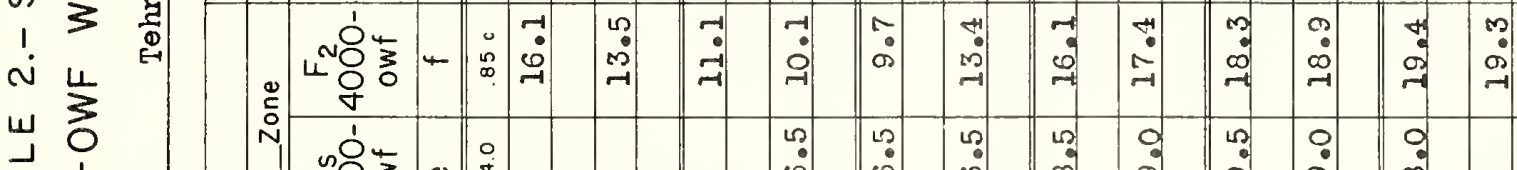

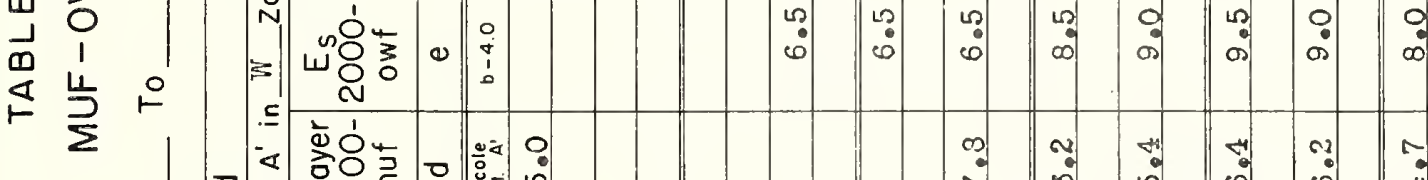

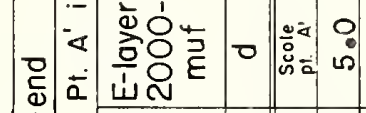

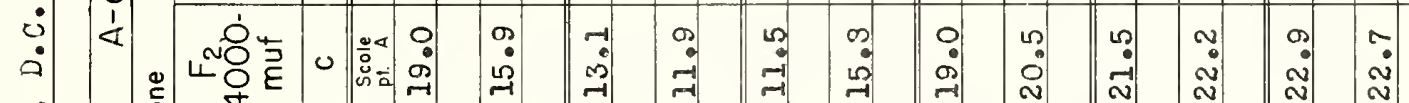

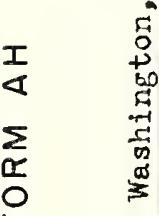

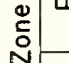

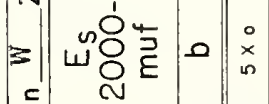

舟

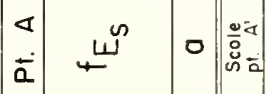

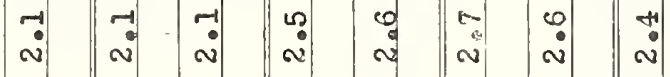

$\stackrel{\substack{a \\ \underline{a}}}{\underline{\underline{\alpha}}}$

占

ป⿱艹

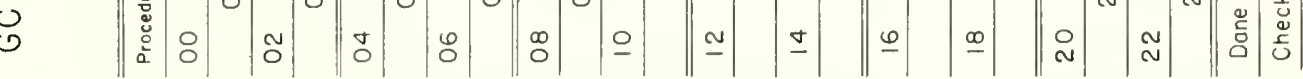




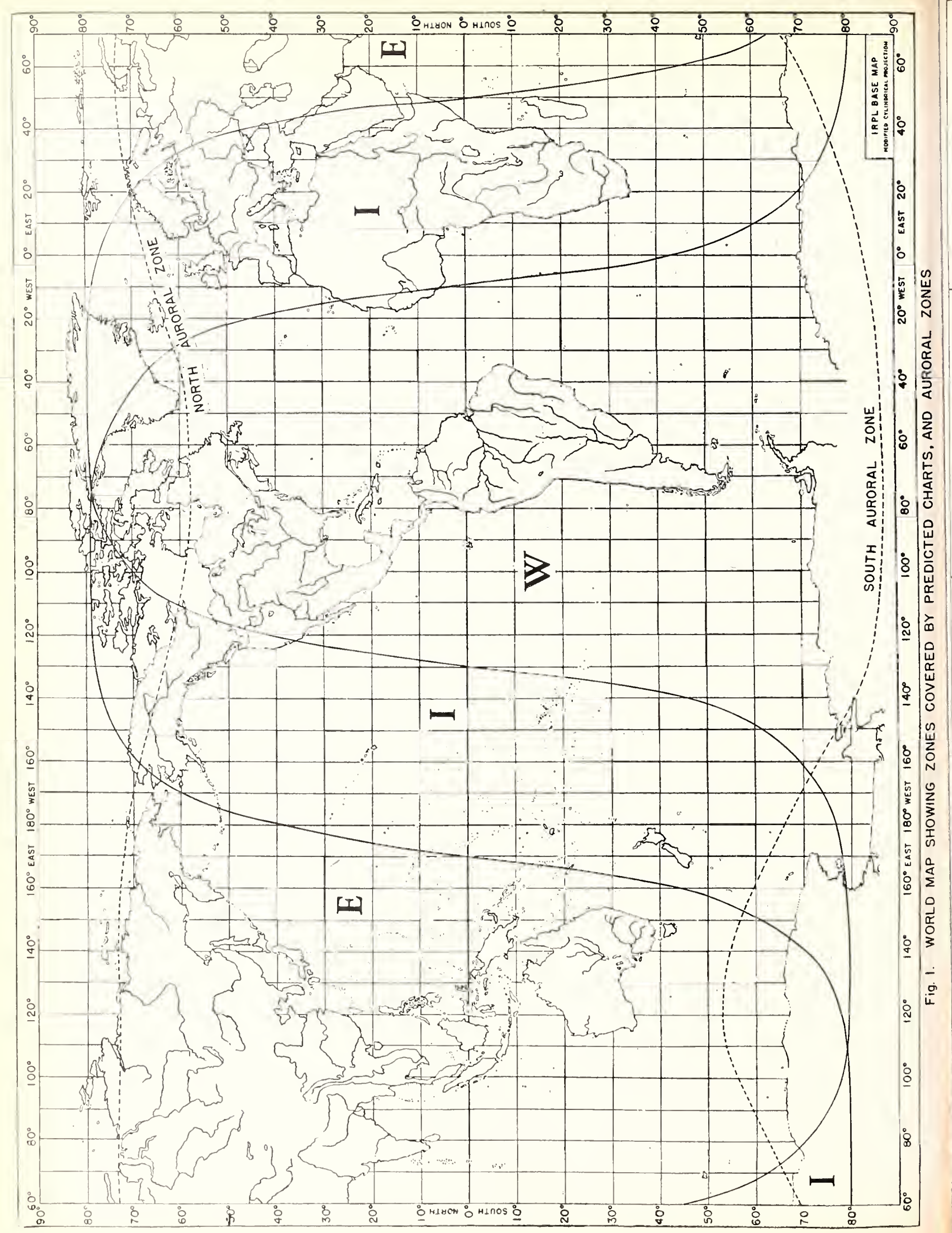



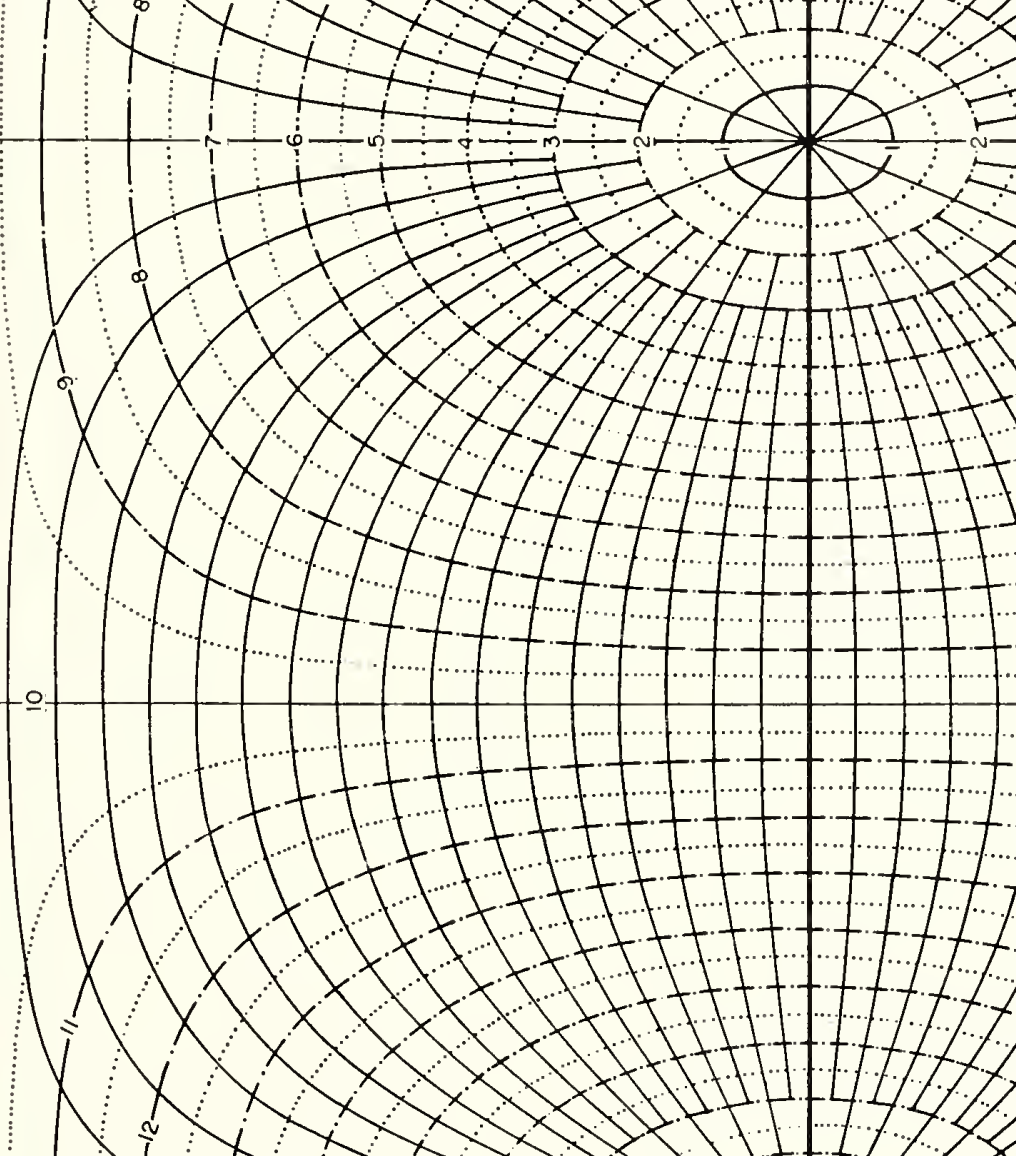


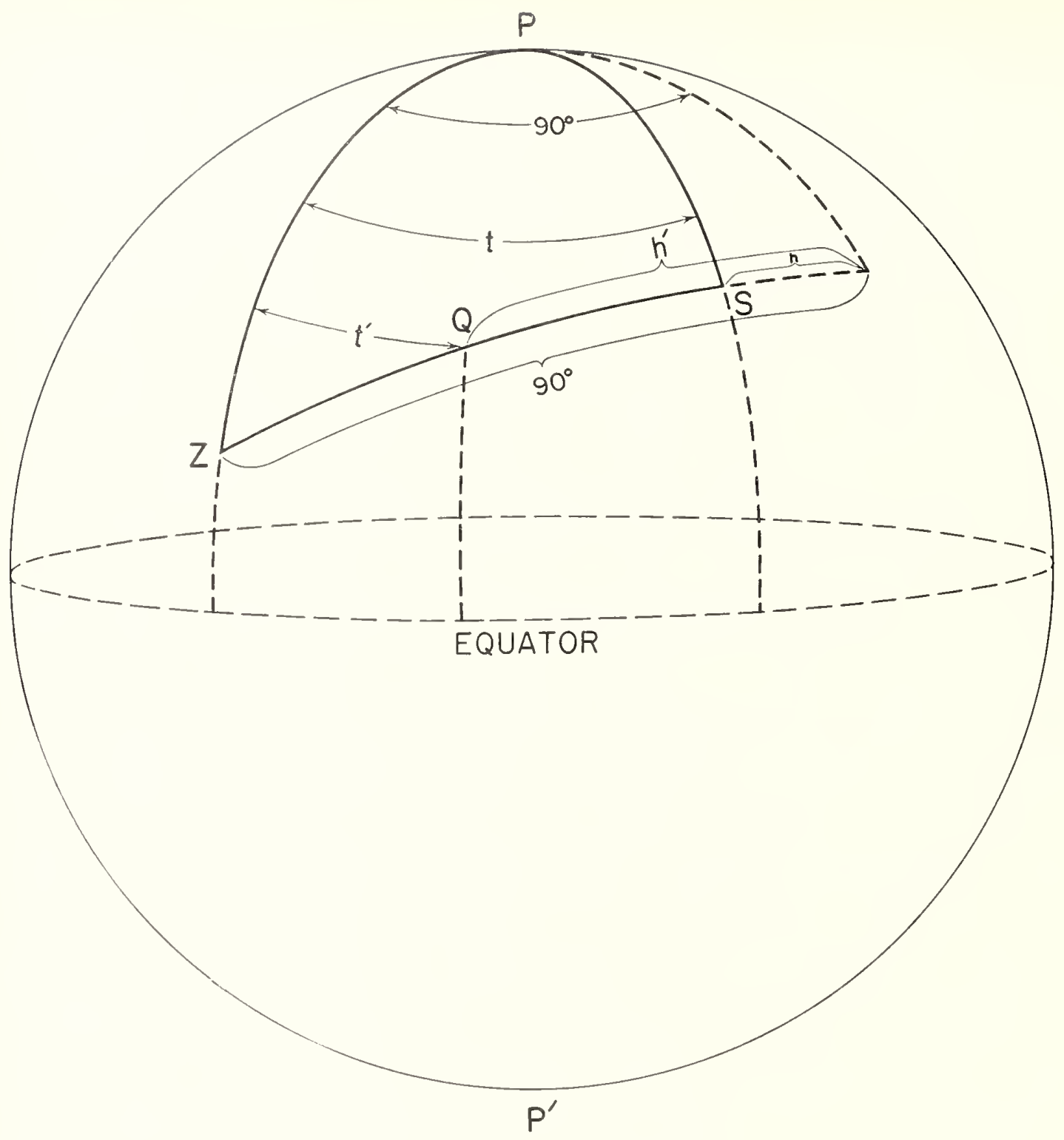

Fig. 3. DIAGRAM OF TRANSMISSION PATH AUXILIARY TO EXPLANATION OF USE OF DISTANCE - BEARING NOMOGRAM, FIG. 4. 
Degrees

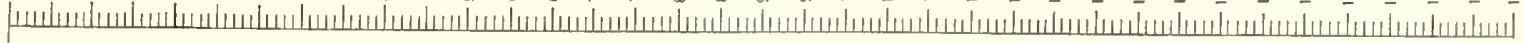

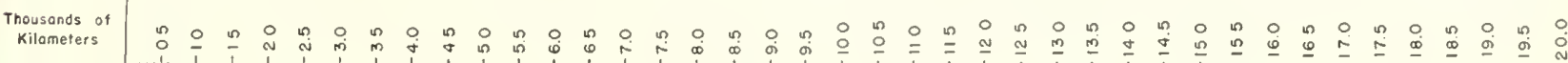

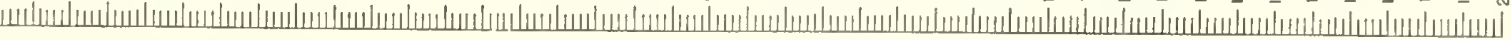

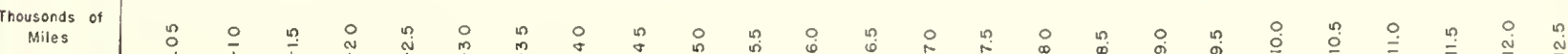

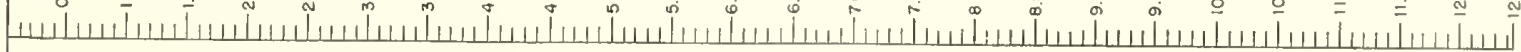
Thousonds of
Nautical Miles

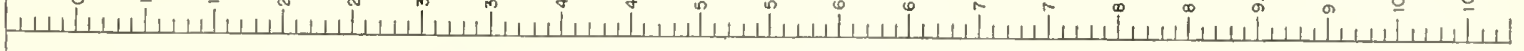

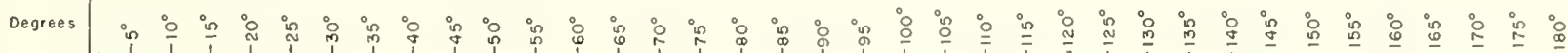

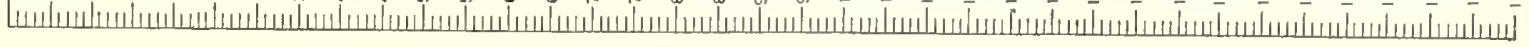

Fin 4. NOMOGRAM (AFTER D'OCAGNE) FOR OBTAINING GREAT-CIRCLE DISTANCES, BEARINGS, LATITUDE AND LONGITUDE OF TRANSMISSION CONTROL POINTS, SOLAR ZENITH ANGLES. CONVERSION SCALE FOR VARIOUS DISTANCE UNITS. 


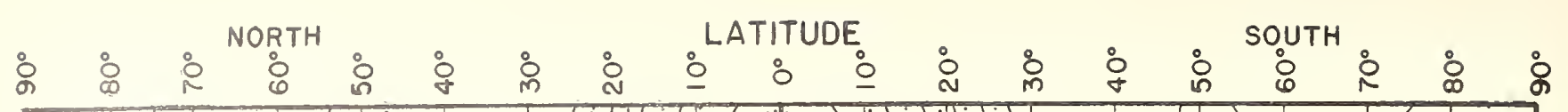

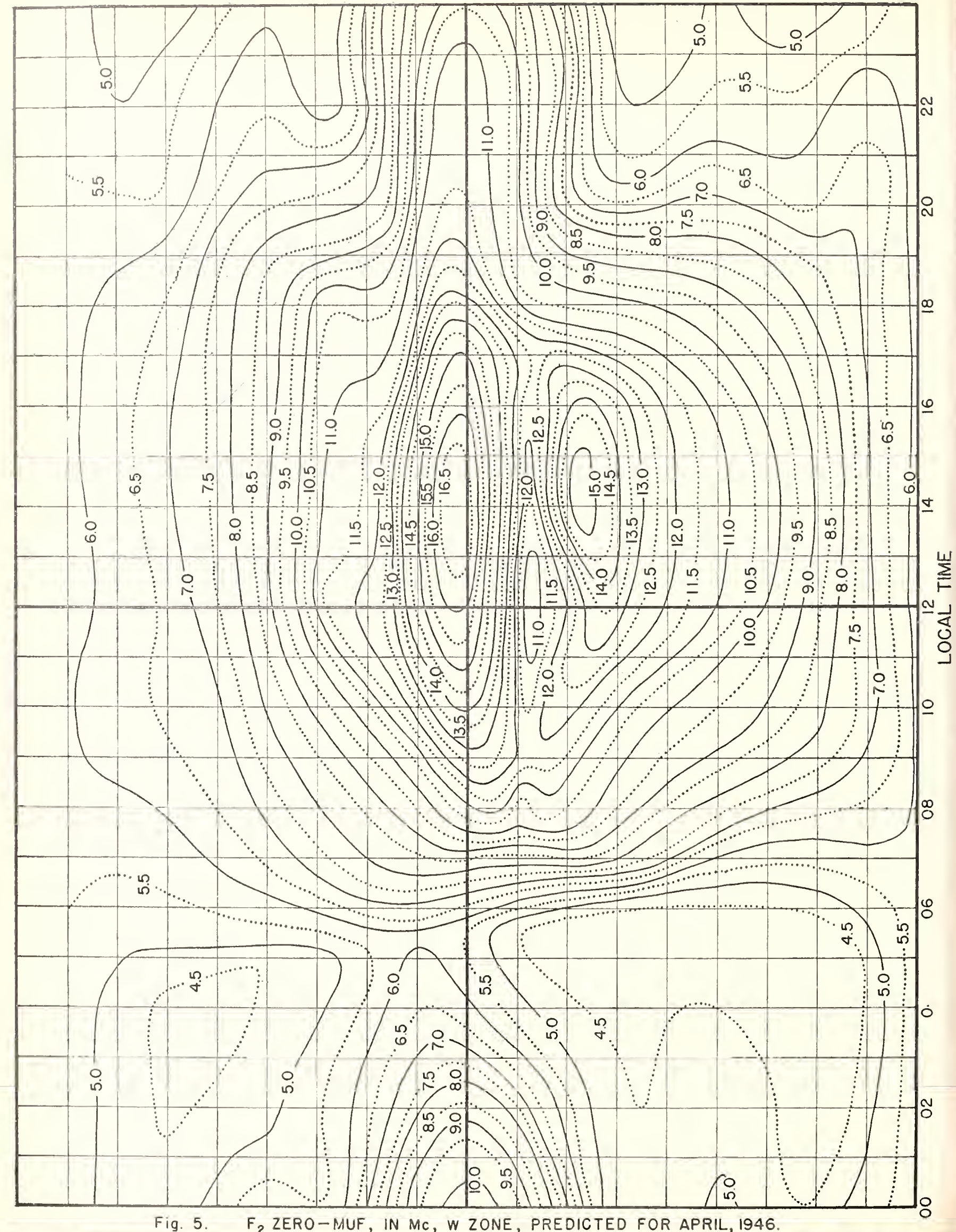


$\therefore$

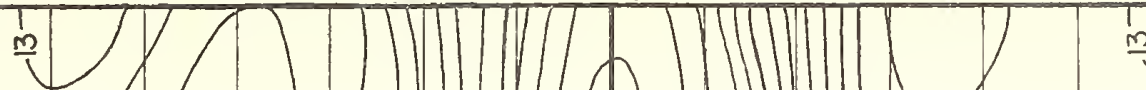
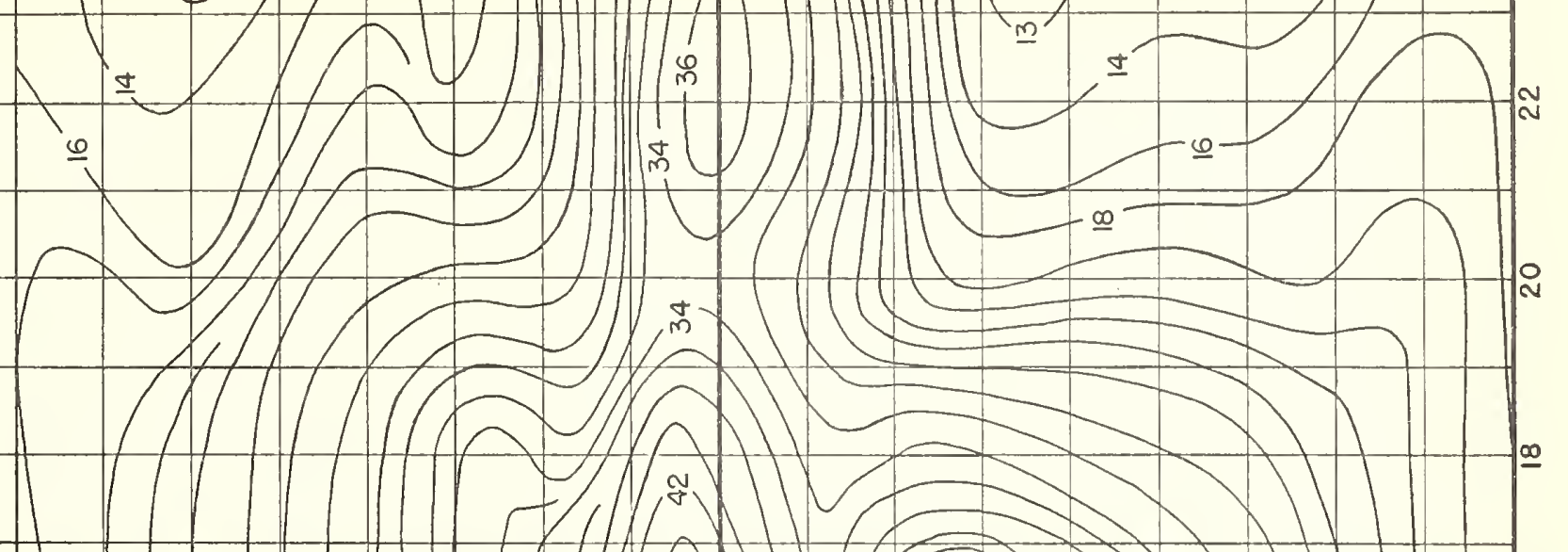

is / /

(m)

1017 ing

ㅇ.

$\underline{\underline{1}}$

啇

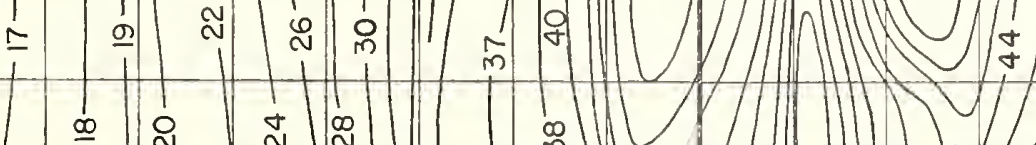

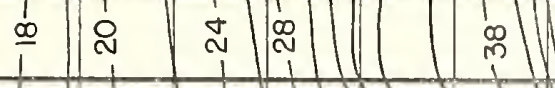

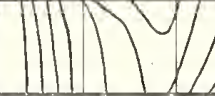

崖

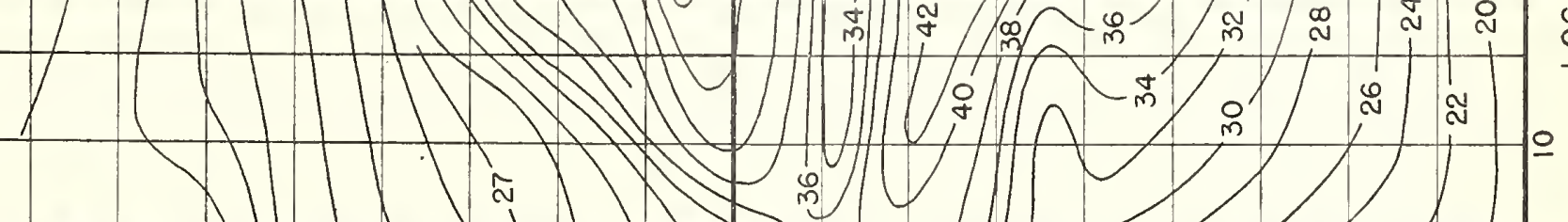

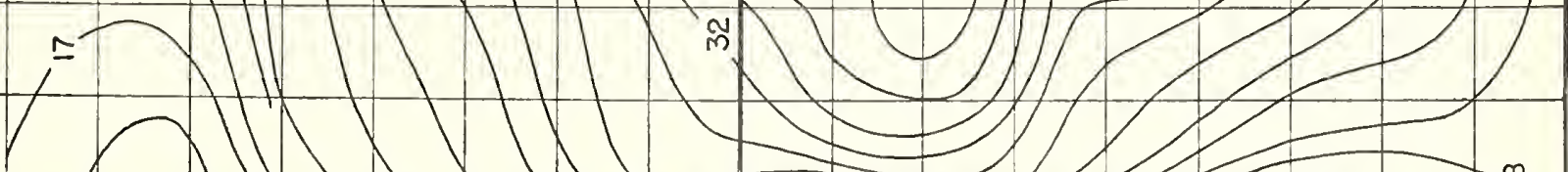

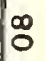

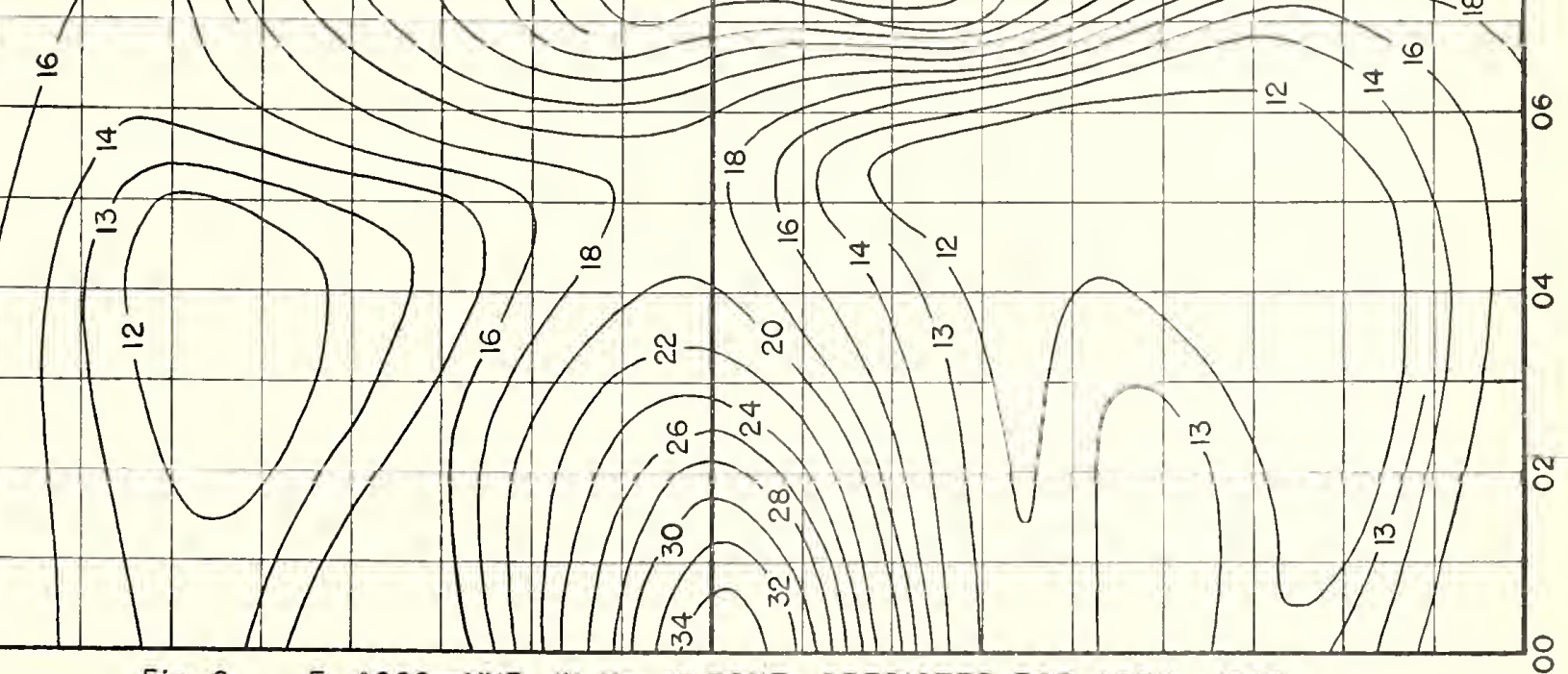

Fig. 6. $F_{2} 4000-M U F$, IN MC, W ZONE, PREDICTEO FOR APRIL, 1946. 


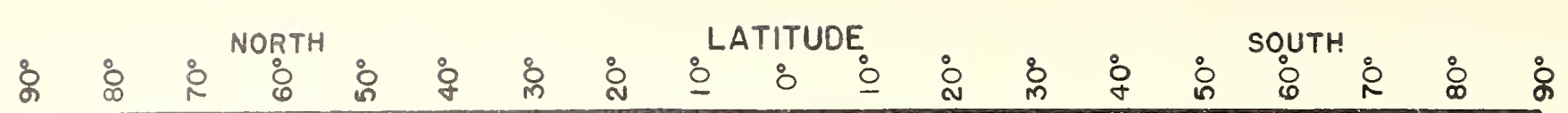
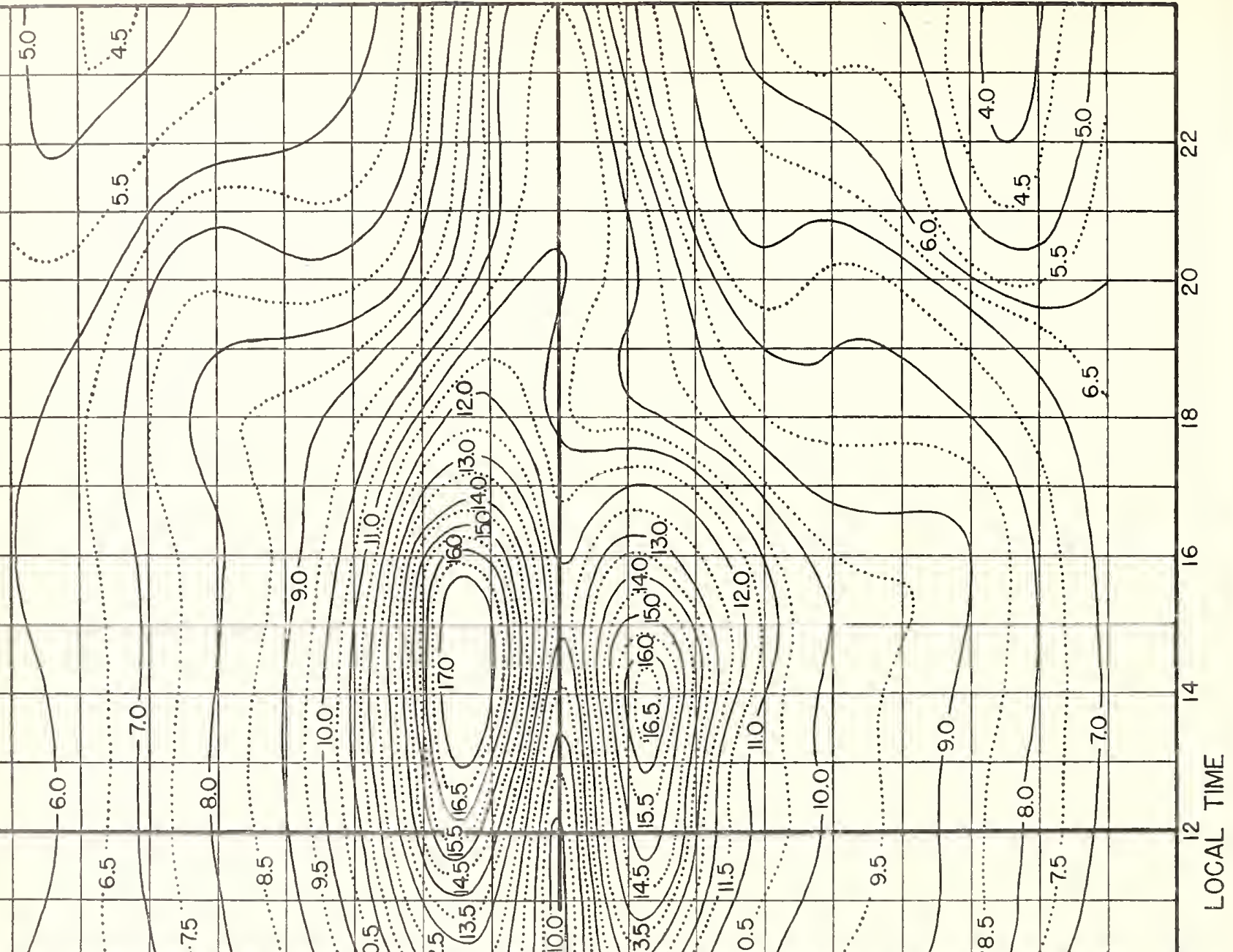

( $\left.)(2)^{2}\right):$

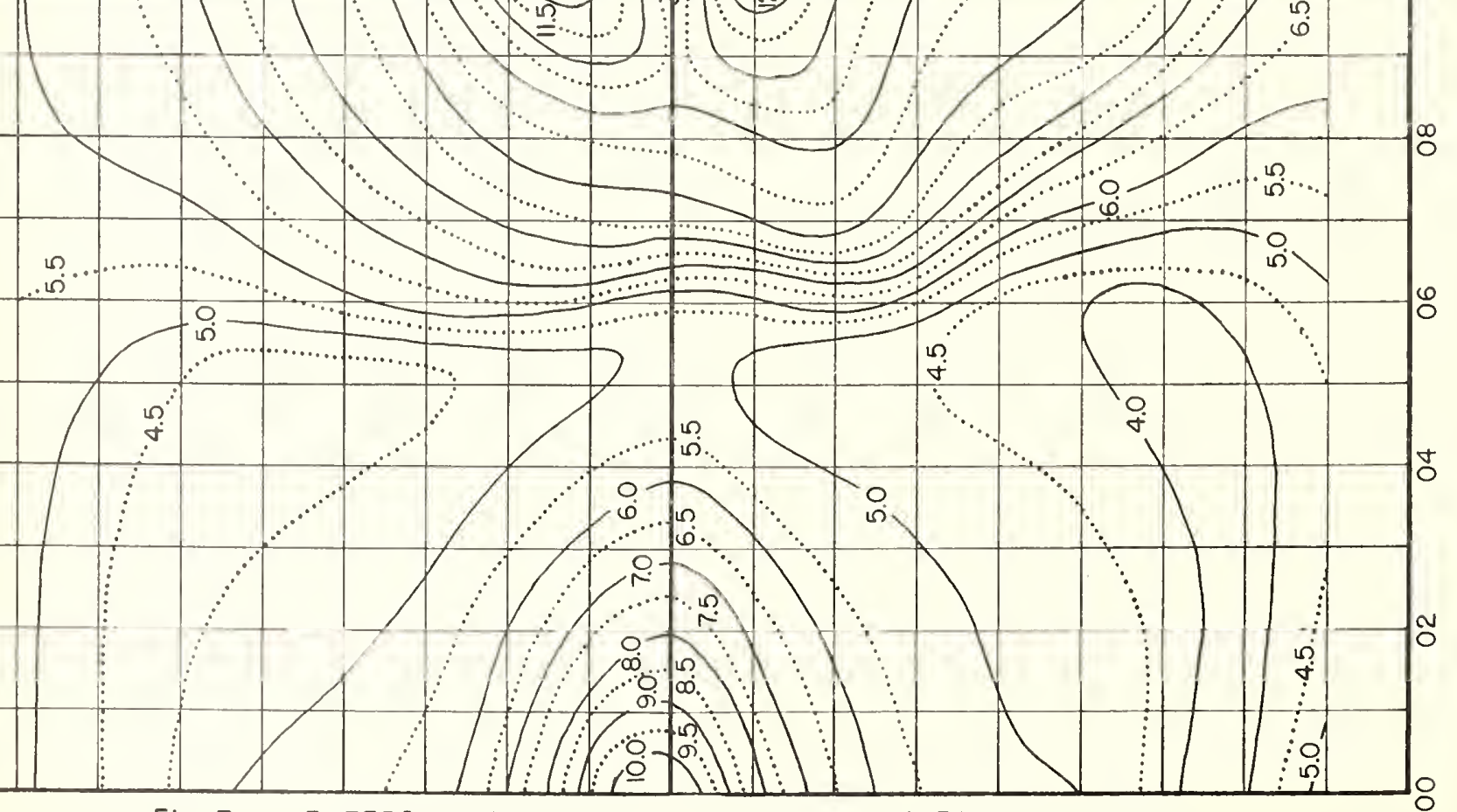

Fig. 7. $F_{2}$ ZERO-MUF, IN MC, I ZONE, PREDICTED FOR APRIL, 1946. 


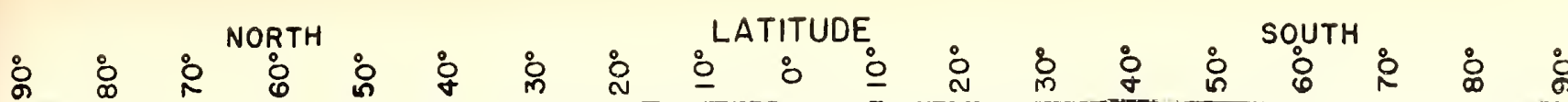

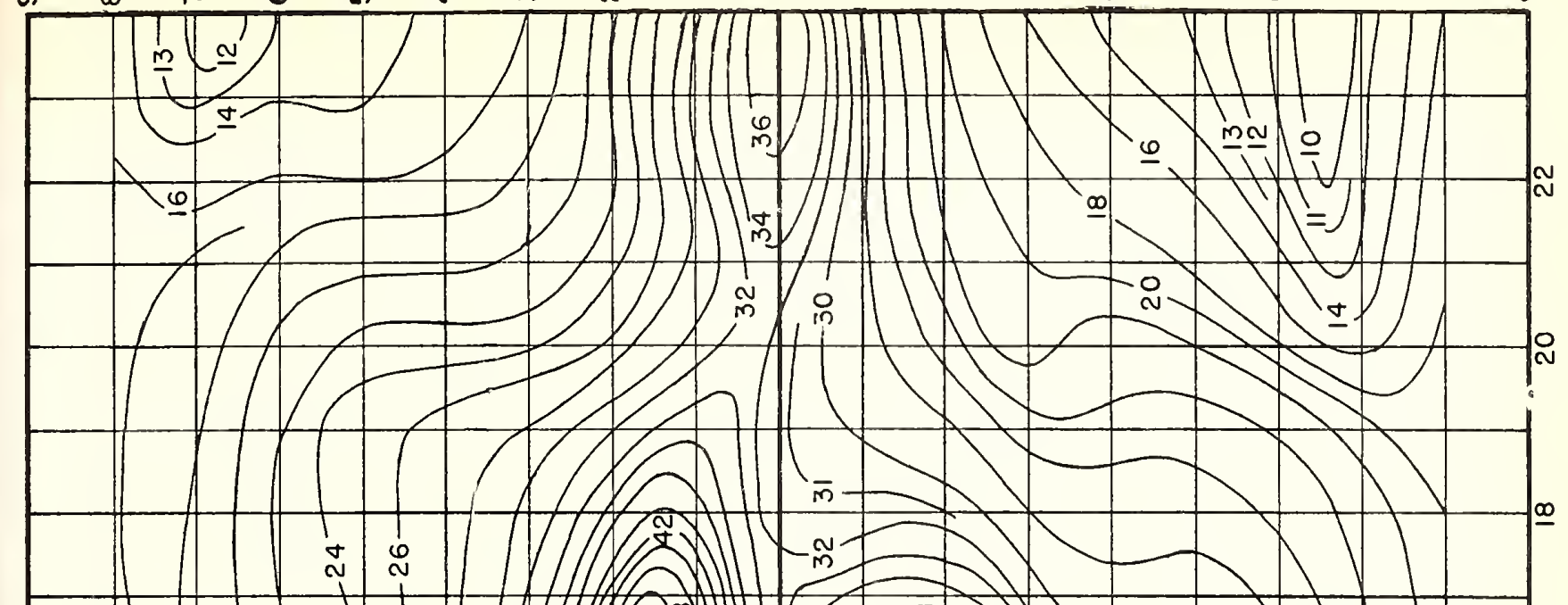

1 $\simeq$ लि

$\left(\begin{array}{c}0 \\ \text { in } \\ 1\end{array}\right)$

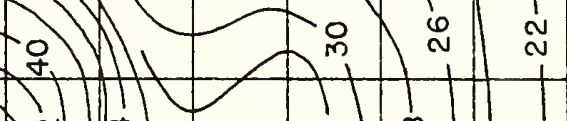
$\underline{\varphi}$

.

$\prod_{\infty}^{\infty}$

(

$\frac{1}{m} \stackrel{\infty}{N}$

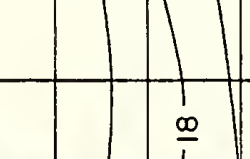

I

$+$

$\left(\begin{array}{c}1 \\ 0 \\ 0 \\ 0\end{array}\right]$

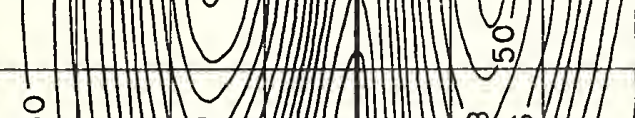

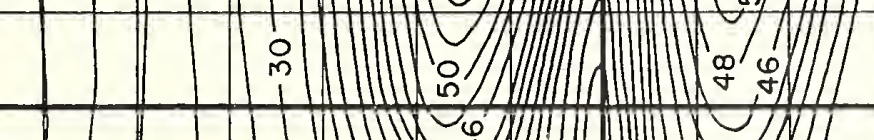

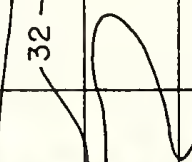

1.

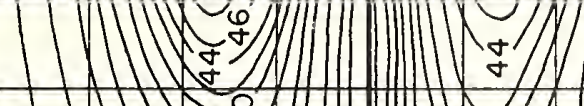

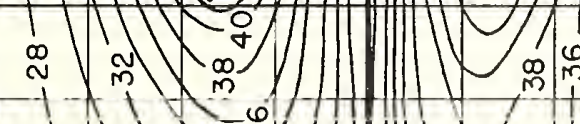

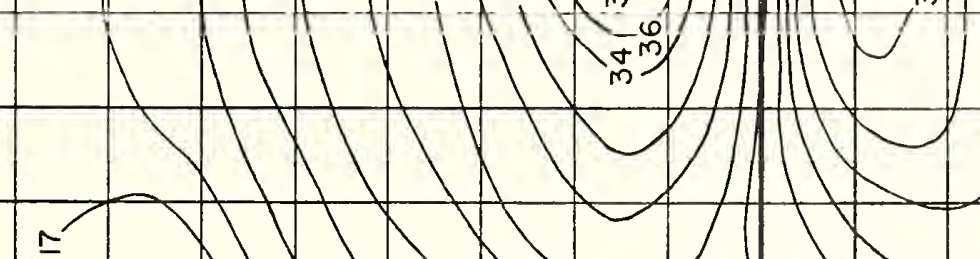

$\sqrt{1}$
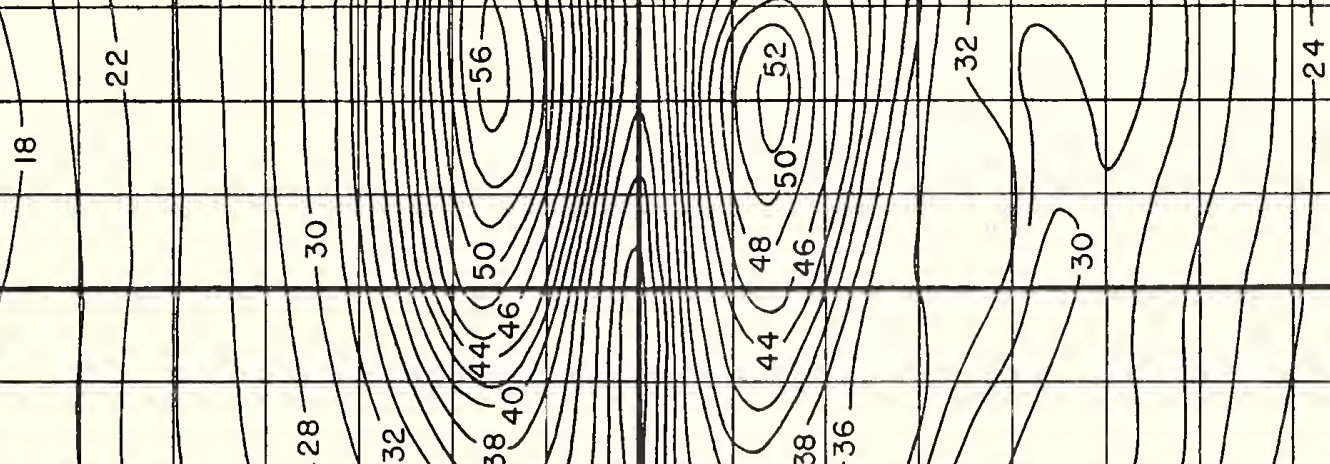
$\pm$

(

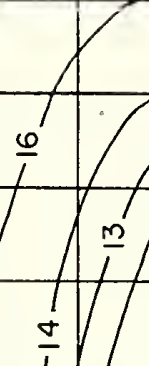
,

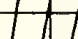
证:

Fig. 8. $F_{2}$ 4O00-MUF, IN MC, I ZONE, PREDICTED FOR APRIL, 1946. 


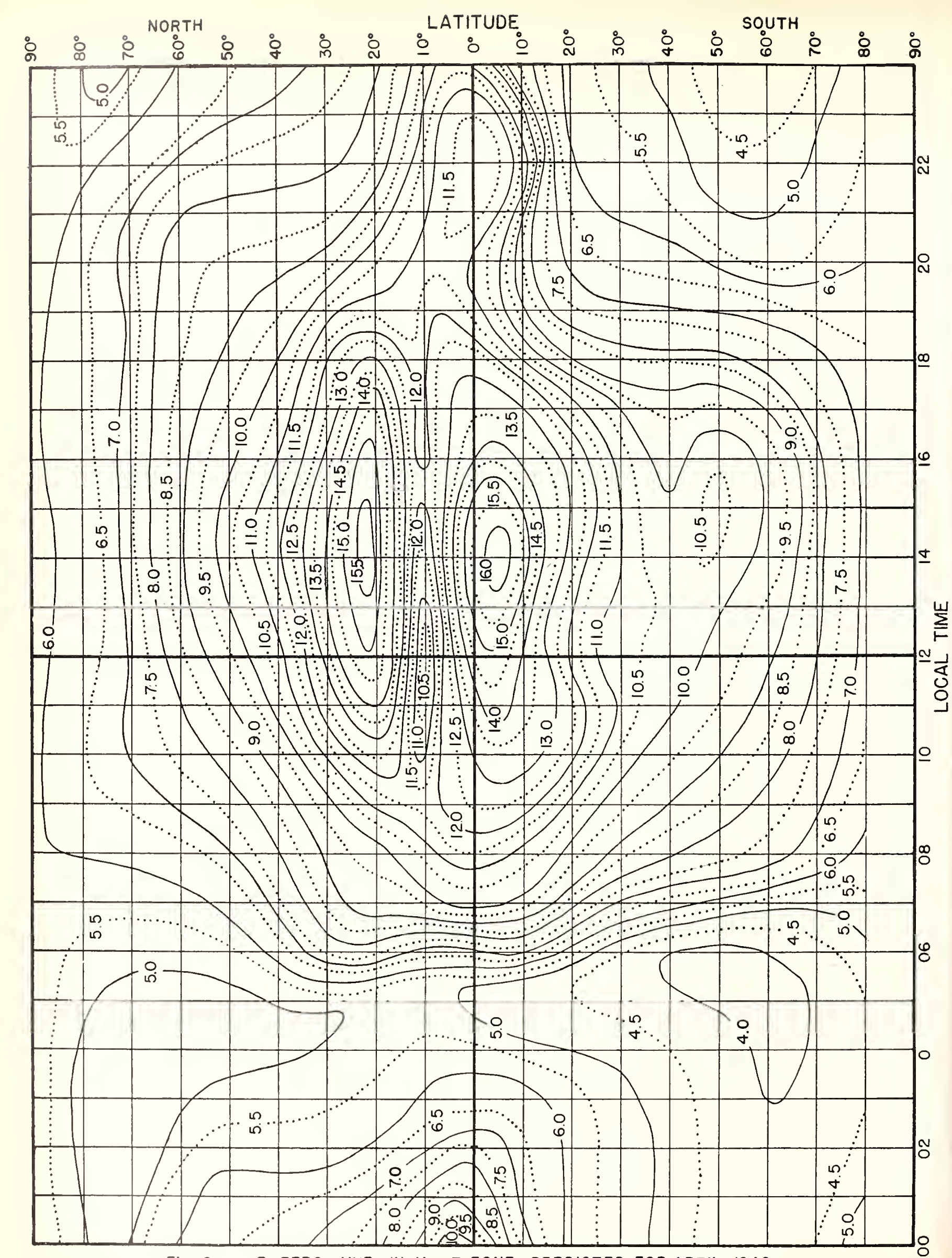

Fig. 9. $F_{2}$ ZERO-MUF, IN MC, E ZONE, PREDICTED FOR APRIL, 1946. 


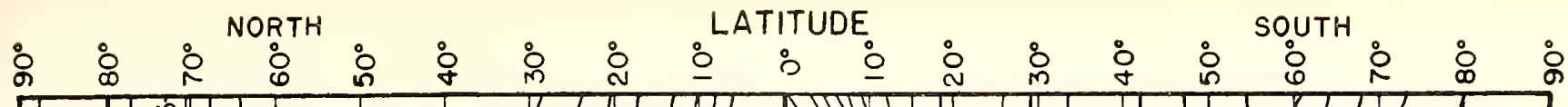

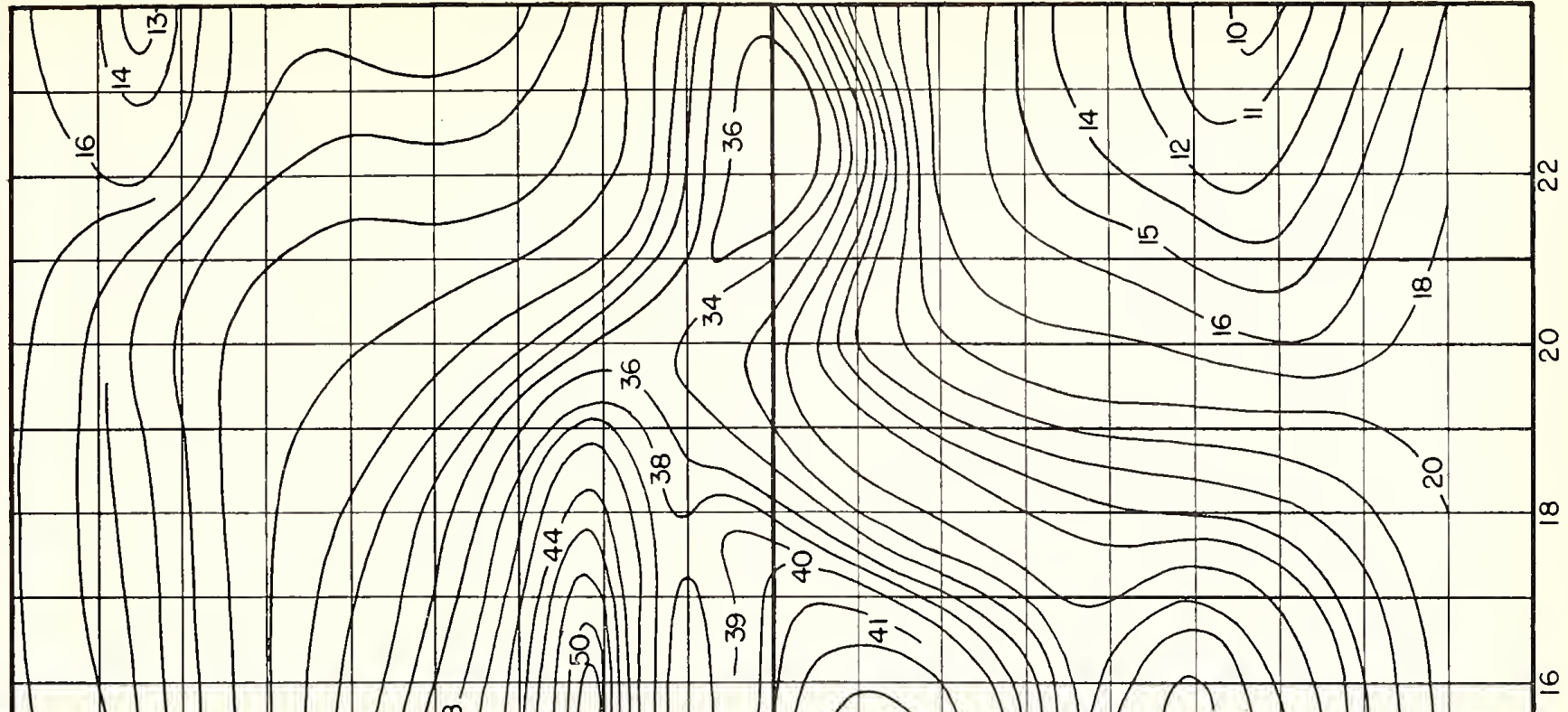

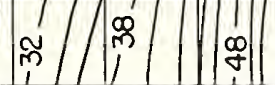

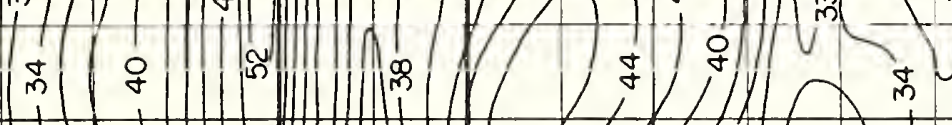

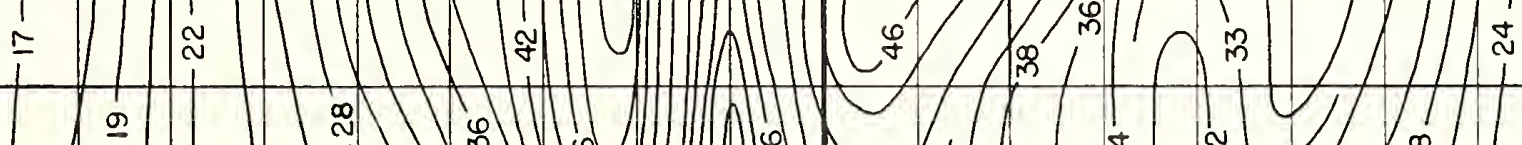

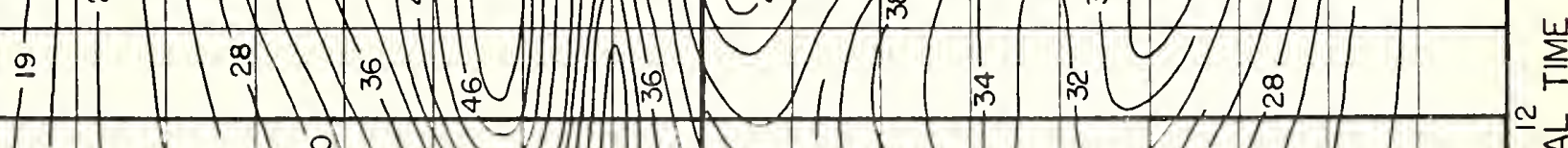

일

舀 (

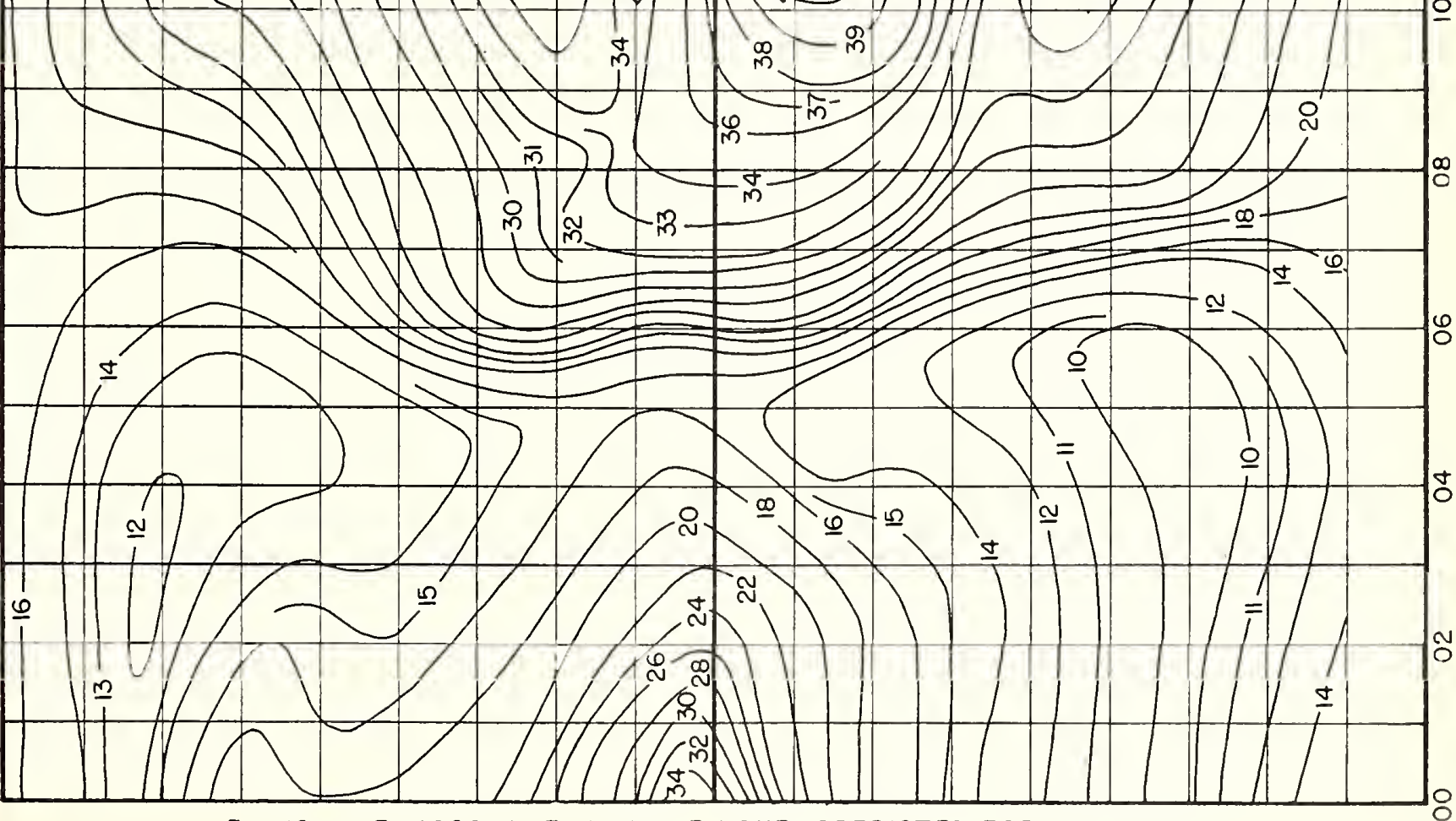

Fig. 10. $F_{2}$ 4000-MUF, IN MC, E ZONE, PREDICTED FOR APRIL, 1946. 


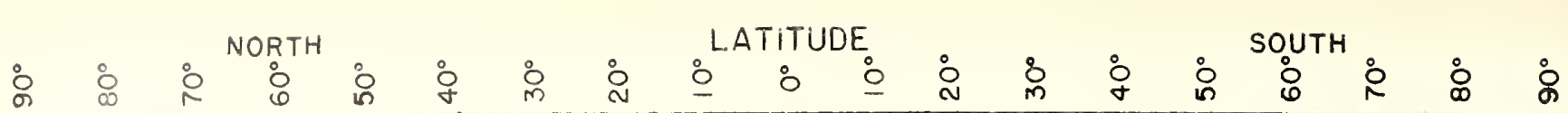
\begin{tabular}{|l|l|l|l|l|l|l|l|l|l|l|l|l|l|l|l|l|}
\hline T1 & 1 & & & & & & & & & & & & & & & \\
\hline
\end{tabular} $\infty \infty_{\infty}^{\infty}$

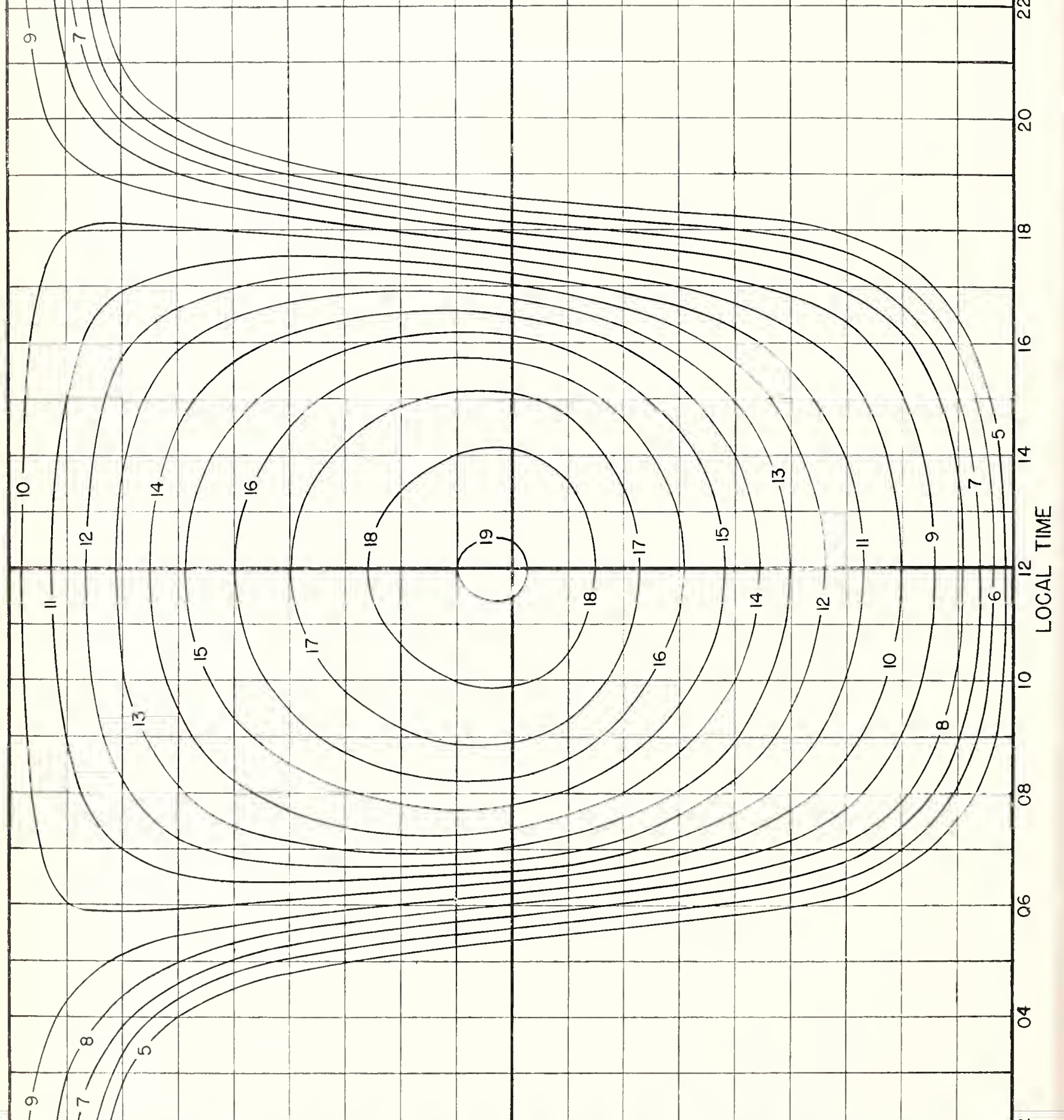




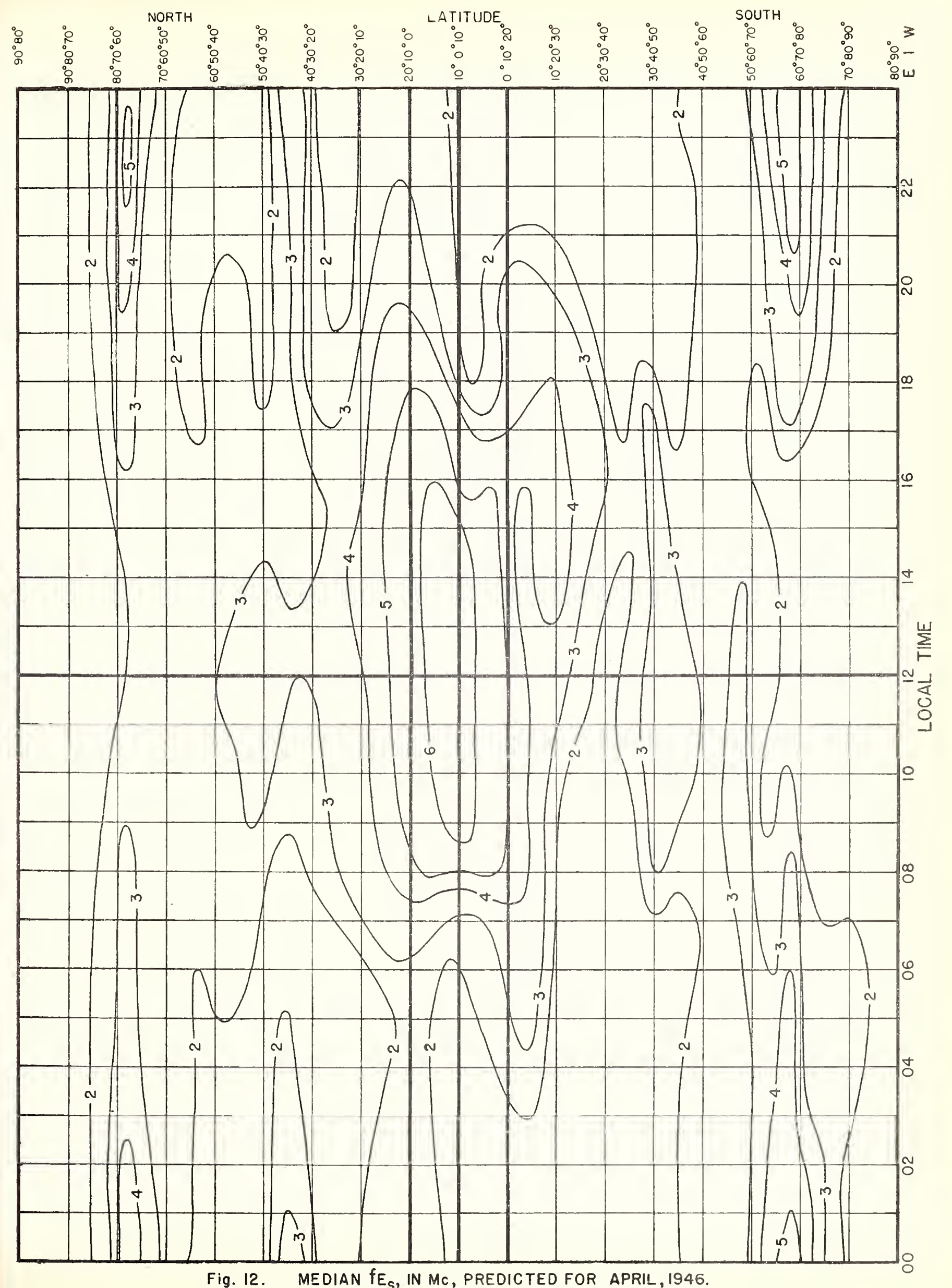


$1 \mathrm{~km}=0.62137$ mile $=0.53961$ nout. $\mathrm{mi}$.

$1 \mathrm{~m}$ le $=160935 \mathrm{~km}=0.86836$ nout. mi.

I nout. $\mathrm{mi}=1.85325 \mathrm{~km}=1.1516 \mathrm{mi}$.

FOR VALUES OF MUF GREATER
THAN 35 MC, MULTIPLY ALL MUF AND OWF SCALES BY 2.
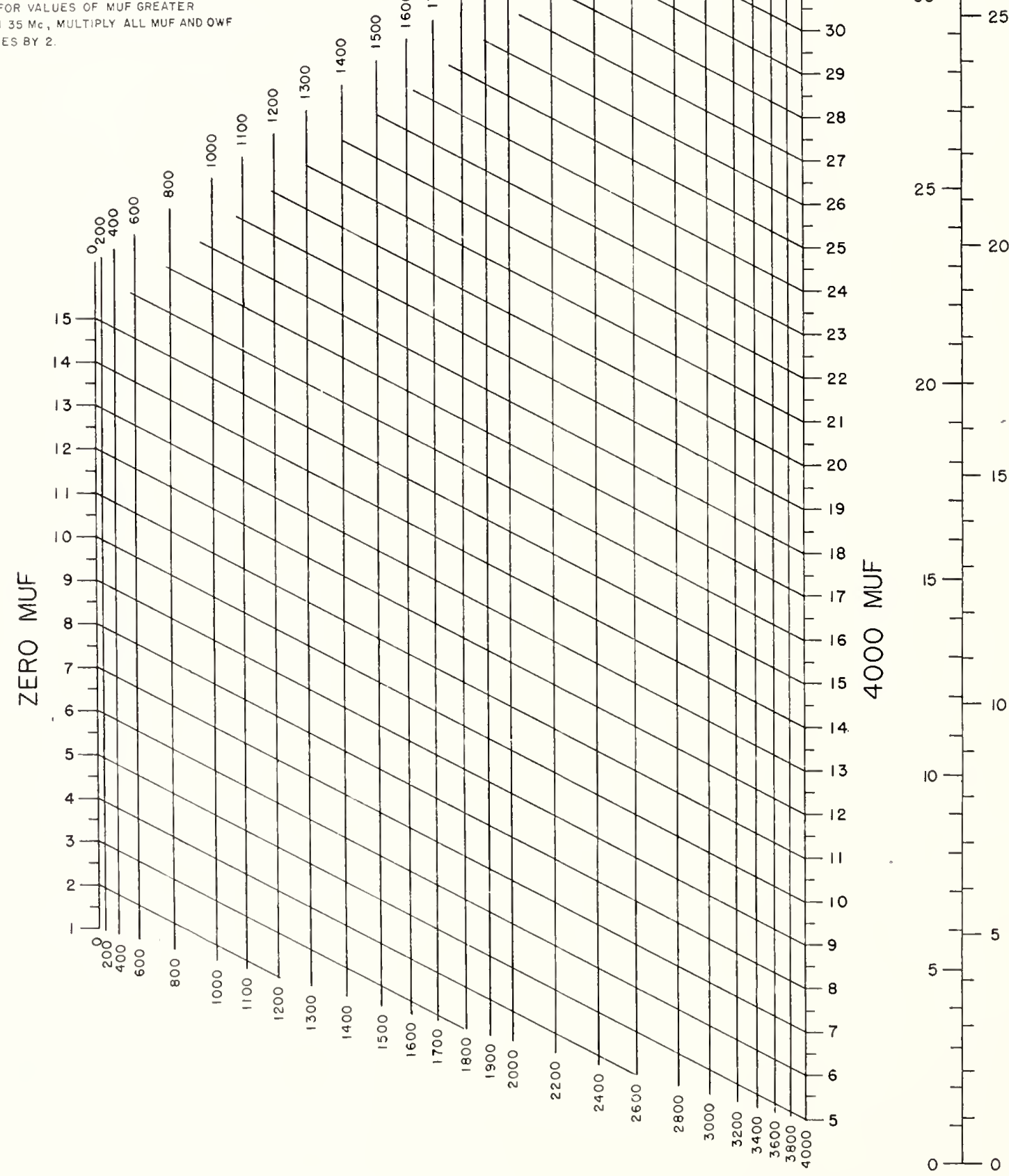

FIG.13. NOMOGRAM FOR TRANSFORMING $F_{2}$-ZERO-MUF AND $F_{2}-4000$-MUF TO EQUIVALENT MAXIMUM USABLE FREQUENCIES AT INTERMEDIATE TRANSMISSION DISTANCES; CONVERSION SCALE FOR OBTAINING OPTIMUM WORKING FREQUENCIES. 


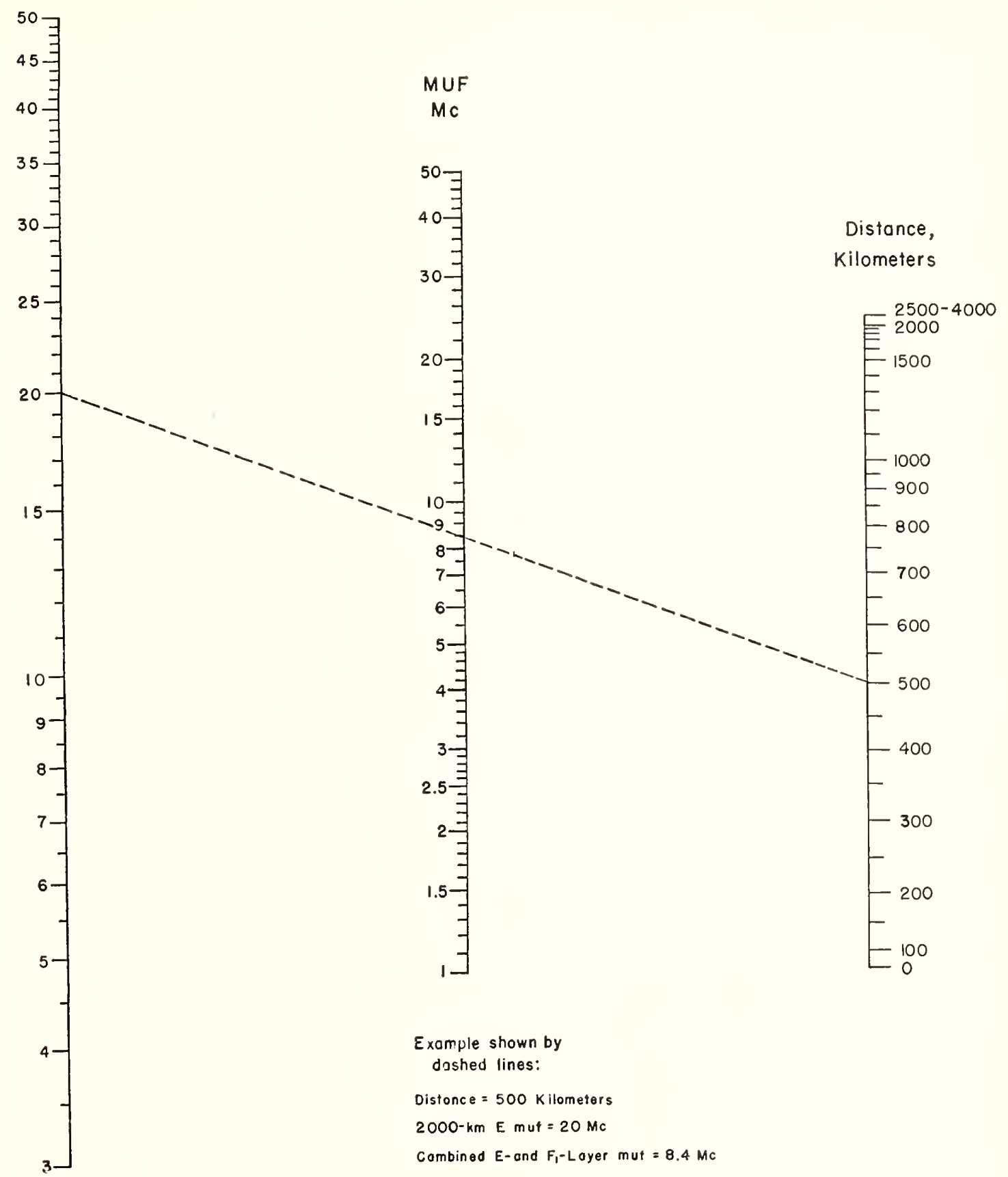

FIG. I4 NOMOGRAM FOR TRANSFORMING E-LAYER 2000-MUF TO EQUIVALENT MAXIMUM USABLE FREQUENCIES AND OPTIMUM WORKING FREQUENCIES DUE TO COMBINED EFFECT OF E LAYER AND F, LAYER AT OTHER TRANSMISSION DISTANCES. 


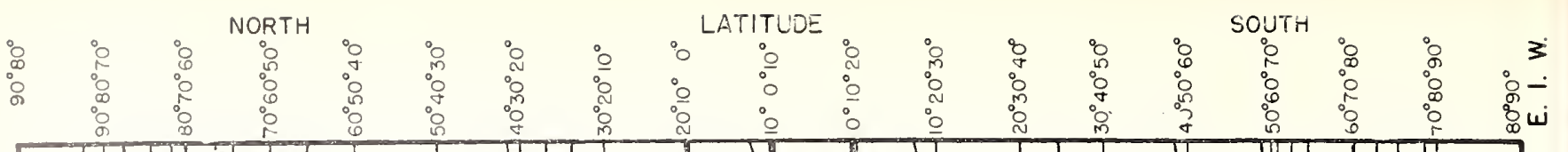

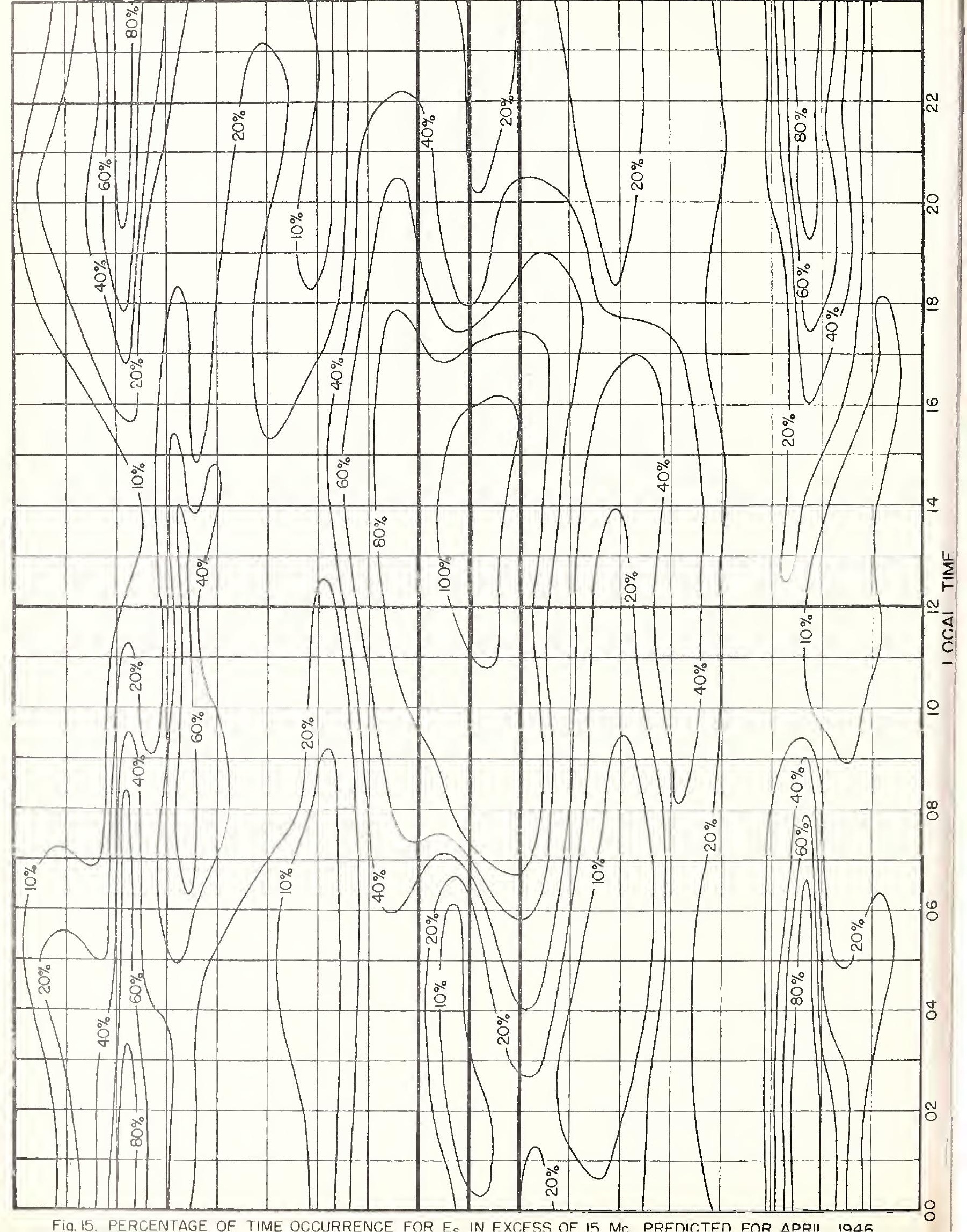



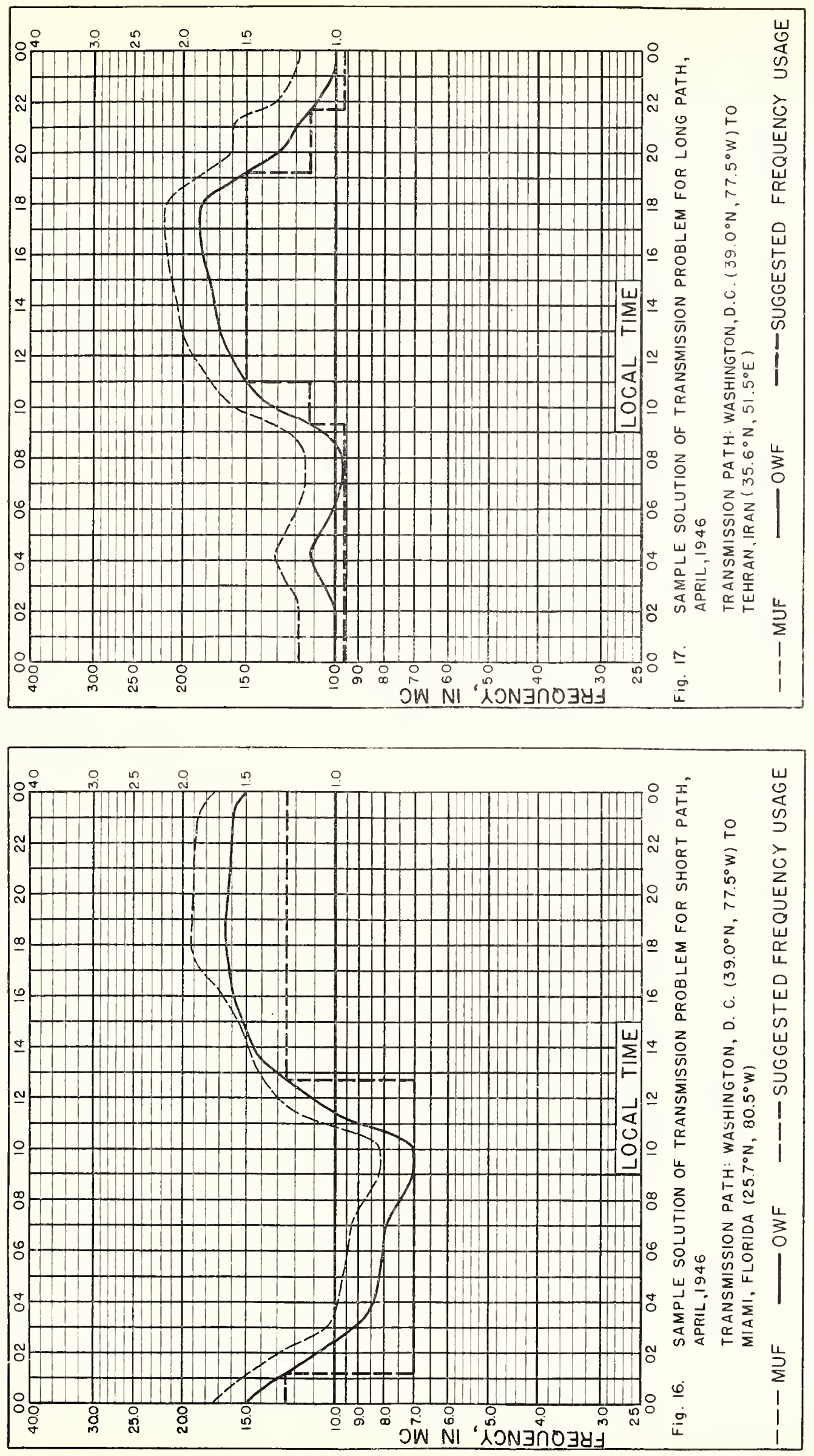




\section{IRPL REPORTS}

Daily:

Telephoned and telegraphed reports of ionospheric, solar, geomagnetic, and radio propagation data from various places.

Radio disturbance warnings.

Semiweekly:

IRPL-J. Radio Propagation Forecast.

Semimonthly:

IRPL-Ja. Semimonthly Frequency Revision Factors for IRPL Basic Radio Propagation Prediction Reports (issued with IRPL-J series from 4 to 7 days in advance). Monthly:

IRPL-D. Basic Radio Propagation Predictions-Three months in advance. War Dept. TB 11-499-, mon hly supplements to TM 11-499; Navy Dept. (DNC-13-1 ( ), monthly supplements to DNC-13-1.)

IRPL-F. Iomospheric Data.

Bimonthly:

IRPL-G. Correlation of D. F. Errors With Ionospheric Conditions.

Ouarterly:

*IRPL-A. Recommended Frequency Bands for Ships and Aircraft in the Atlantic and Pacific.

IRPL-B. Recommended Frequency Bands for Submarines in the Pacific.

*IRPL-H. Frequency Guide for Operating Personnel.

**TRPL-M. Frequency Guide for Merchant Ships.

Special Reports, etc.:

IRPI Radio Propagation Handbook, Part 1. (War Dept. TM 11-499; Navy Dept. DNC-13-1.)

IRPL-C1 through C61. Reports and papers of the International Radio Propagation Conference, 17 April to 5 May 1944

IRPL-R. Unscheduled reports:

R1. Maximum Usable Frequency Graph paper.

$\mathrm{R} 2$ and R3. Obsolete.

R4. Methods Used by IRPL for the Prediction of Ionosphere Characteristics and Maximum Usable Frequencies.

R5. Criteria for Ionospheric Storniness.

R6. Experimental studies of ionospheric propagation as applied to a navigation system.

R7. Further studies of ionospheric propagation as applied to a navigation system.

R8. The Prediction of Usable Frequencies Over a Path of Short or Medium Length, Including the Effects of Es.

R9. An Automatic Instantaneous Indicator of Skip Distance and MUF.

R10. A method of study of the ionosphere.

R11. A Nomographic Method for Both Prediction and Observation Correlation of Ionosphere Characteristics.

R12. Ionospheric variations.

R13. Ionospheric and Radio Propagation Disturbances, October 1943 through February 1945.

R14. A Graphical Method for Calculating Ground Reflection Coefficients.

R15. Predicted Limits for $F 2$-layer Radio Transmission Throughout the Solar Cycle.

R16. Predicted $F$-layer Frequencies Throughout the Solar Cycle, for Summer, Winter, and Equinox Season.

R17. Japanese Ionospheric Data-1943.

R18. Comparison of Geomagnetic Records and North Atlantic Radio Propagation Quality Figures-October 1943 through May 1945.

R19. Nomographic Prediction of F2-layer Frequencies Throughout the Solar Cycle, for June.

R20. Nomographic Predictions of F2-layer Frequencies Throughout the Solar Cycle, for September.

R21. Notes on the Preparation of Skip-Distance and MUF Charts for Use by Direction-Finder Stations. (For distances out to $4000 \mathrm{~km}$.)

R22. Nomographic Predictions of F2-layer Frequencies Throughout the Solar Cycle, for December.

R23. Solar-Cycle Data for Correlation with Radio Propagation Phenomena.

R24. Effect of certain equipment characteristics on the usefulness of a navigation system.

R25. The Prediction of Solar Activity as a Basis for the Prediction of Radio Propagation Phenomena.

R26. The Ionosphere as a Measure of Solar Activity.

IRPL-T. Reports on Tropospheric Propagation.

T1. Radar Operation and Weather. (Superseded by JANP 101).

T2. Radar coverage and weather. (Superseded by JANP 102.)

*Items bearing this symbol are distributed only by U. S. Navy in NONREGISTERED PUBLICATIONS MEMORANDA (NRPM).

**Distributed only by U.S. Navy. 
